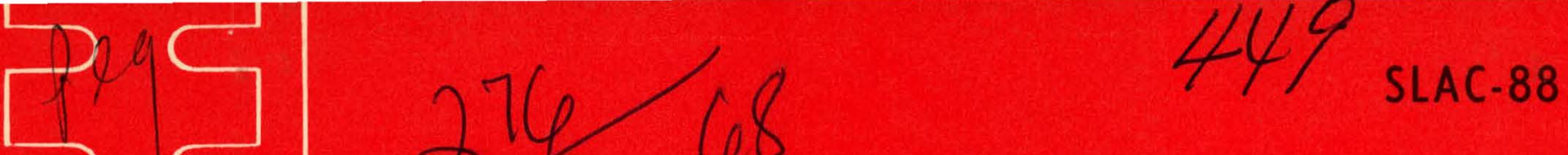

\title{
AN ANALYSIS OF TRANSIENTS IN TUNNEL-DIODE CIRCUITS
}

Arpad Barna

\section{SLAC REPORT NO, 88}

August 1968

AEC Contract AT(04-3)-515

STANFORD LINEAR ACCELERATOR CENTER Stanford University - Stanford, California 


\section{DISCLAIMER}

This report was prepared as an account of work sponsored by an agency of the United States Government. Neither the United States Government nor any agency Thereof, nor any of their employees, makes any warranty, express or implied, or assumes any legal liability or responsibility for the accuracy, completeness, or usefulness of any information, apparatus, product, or process disclosed, or represents that its use would not infringe privately owned rights. Reference herein to any specific commercial product, process, or service by trade name, trademark, manufacturer, or otherwise does not necessarily constitute or imply its endorsement, recommendation, or favoring by the United States Government or any agency thereof. The views and opinions of authors expressed herein do not necessarily state or reflect those of the United States Government or any agency thereof. 


\section{DISCLAIMER}

Portions of this document may be illegible in electronic image products. Images are produced from the best available original document. 


\section{AN ANALYSIS OF TRANSIENTS IN TUNNEL-DIODE CIRCUITS}

by

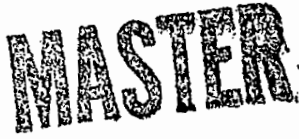

Arpad Barna

August, 1968

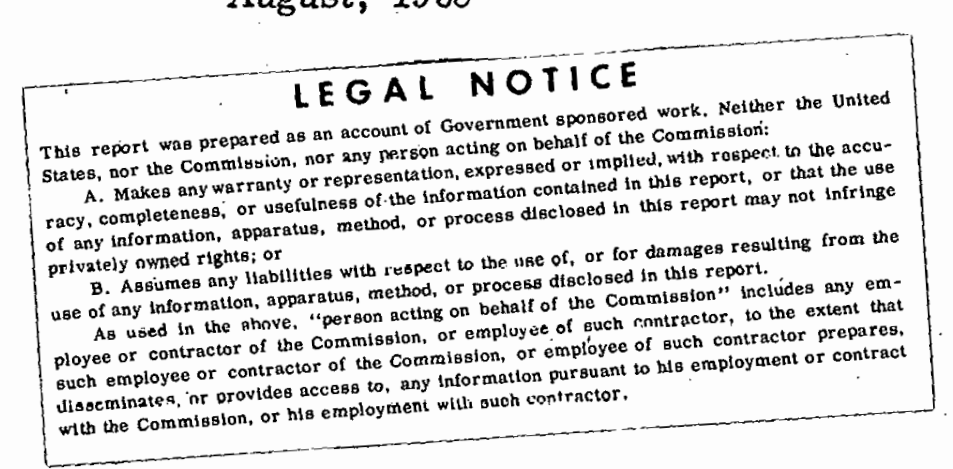

\section{Technical Report}

Prepared Under

Contract AT(04-3)-515

for the USAEC

San Francisco Operations Office

Printed in USA. Available from CFSII, National Bureau of Standards, U. S. Department of Commerce, Springfield, Virgina 22151

Price: Printed Copy $\$ 3.00$; Microfiche $\$ 0.65$ 
THIS PAGE

\section{WAS INTENTIONALLY LEFT BLANK}




\begin{abstract}
An analysis is performed for the transient response of a tunnel-diode modeled by a circuit of two capacitances, an inductor, and the de i-v characteristic of the diode. The nonlinear differential equations of the transition are solved numerically, and waveforms are presented for a wide range of circuit parameters.
\end{abstract}




\section{LIST OF FIGURES}

$\underline{\text { Page }}$

1. Tunnel-diode circuitry .................. 2

2. Tunnel-diode dc current versus voltage characteristic . . . . 3

3. Flow-chart of the computer program ............ 4

4. Normalized output voltage as function of normalized time with the normalized drive current slope as parameter for $\mathrm{C}_{2} / \mathrm{C}_{1}=0.02$ with

(a) $\mathrm{L}=0.1 \ldots \ldots \ldots \ldots$

(b) $\mathrm{L}=0.2 \ldots \ldots \ldots$

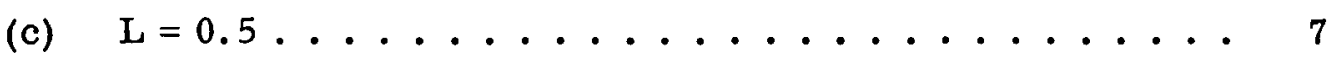

(d) $\mathrm{L}=1.0 \ldots \ldots \ldots \ldots \ldots$

(e) $\mathrm{L}=2.0 \ldots \ldots \ldots \ldots$

(f) $\mathrm{L}=5.0 \ldots \ldots \ldots 10$

5. Normalized output voltage as function of normalized time with the normalized drive current slope as parameter for $\mathrm{C}_{2} / \mathrm{C}_{1}=0.05$ with

(a) $\mathrm{L}=0.1 \ldots \ldots \ldots 11 . \ldots \ldots$

(b) $\mathrm{L}=0.2 \ldots \ldots \ldots 12$

(c) $\quad \mathrm{L}=0.5 \ldots \ldots \ldots \ldots$

(d) $\quad \mathrm{L}=1.0 \ldots \ldots \ldots 14$

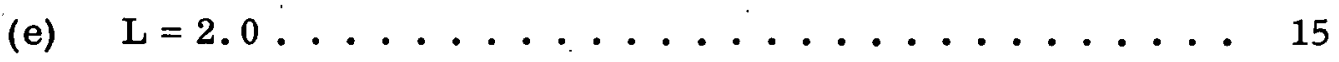

(f) $\quad \mathrm{L}=5.0 \ldots \ldots \ldots \ldots$

6. Normalized output voltage as function of normalized time with the normalized drive current slope as parameter for $\mathrm{C}_{2} / \mathrm{C}_{1}=0.1$ with

(a) $\mathrm{L}=0.1 \ldots \ldots \ldots \ldots$

(b) $\mathrm{L}=0.2 \ldots \ldots \ldots \ldots \ldots \ldots$

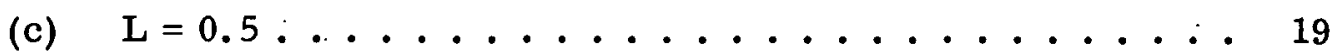

(d) $\mathrm{L}=1.0 \ldots \ldots \ldots \ldots$

(e) $\mathrm{L}=2.0 \ldots \ldots \ldots 21$

(f) $\quad \mathrm{L}=5.0 \ldots \ldots \ldots 22$ 
7. Normalized output voltage as function of normalized time with the normalized drive current slope as parameter for $\mathrm{C}_{2} / \mathrm{C}_{1}=0.2$ with

(a) $\mathrm{L}=0.1 \ldots \ldots 23$

(b) $\mathrm{L}=0.2 \ldots \ldots \ldots 24$

(c) $\mathrm{L}=0.5 \ldots \ldots \ldots 25$

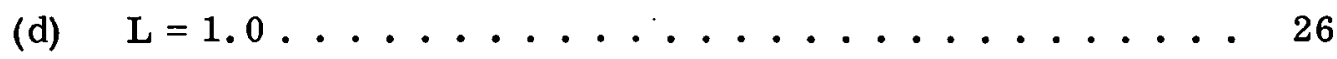

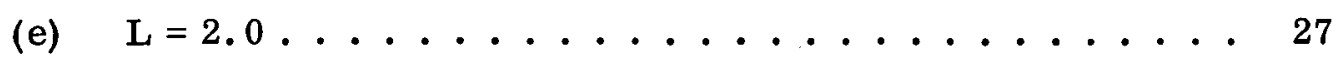

(f) $\quad \mathrm{L}=5.0 \ldots \ldots \ldots \ldots \ldots$

8. Normalized output voltage as function of normalized time with the normalized drive current slope as parameter for $\mathrm{C}_{2} / \mathrm{C}_{1}=0.5$ with

(a) $\mathrm{L}=0.1 \ldots \ldots . \ldots . \ldots . \ldots . \ldots 29$

(b) $\quad \mathrm{L}=0.2 \ldots \ldots 30$

(c) $\mathrm{L}=0.5 \ldots \ldots . \ldots \ldots$

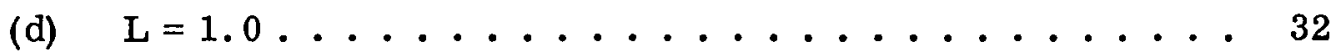

(e) $\quad \mathrm{L}=2.0 \ldots \ldots \ldots 33$

(f) $\quad \mathrm{L}=5.0 \ldots \ldots \ldots \ldots \ldots$

9. Normalized output voltage as function of normalized time with the normalized drive current slope as parameter for $\mathrm{C}_{2} / \mathrm{C}_{1}=1.0$ with

(a) $\mathrm{L}=0.1 \ldots \ldots \ldots . \ldots \ldots$

(b) $\quad \mathrm{L}=0.2 \ldots \ldots \ldots \ldots$

(c) $\quad \mathrm{L}=0.5 \ldots \ldots \ldots \ldots$

(d) $\quad \mathrm{L}=1.0 \ldots \ldots . \ldots \ldots$

(e) $\quad \mathrm{L}=2.0 \ldots \ldots \ldots \ldots$

(f) $\quad \mathrm{L}=5.0 \ldots \ldots \ldots . \ldots \ldots$

10. Fortran-H computer program .............. 41 
The transient response for a ramp-function drive current of a tunneldiode, modeled by a capacitance parallel with a voltage-varying resistor, was analyzed in a previous paper. ${ }^{1}$ In this report the analysis is extended to the model of Fig. 1 incorporating an inductance and two capacitances. The dc $\mathrm{i}-\mathrm{v}$ characteristic of the tunnel-diode is described by the function $i_{D}=I_{p}\left[e \cdot\left(v_{D} / V_{p}\right) \cdot \exp \left(-v_{D} / V_{p}\right)+5 \times 10^{-10} \exp \left(3 v_{D} / V_{p}\right)\right]$ shown in Fig. 2 .

The differential equations of the transient were converted to difference equations and computed on the IBM $360 / 75$ digital computer utilizing a program with the flow-chart of Fig. 3; the Fortran-H program is shown in Fig. 10. Waveforms of the normalized output voltage $\mathrm{V} \equiv \mathrm{v}_{\mathrm{out}} / \mathrm{V}_{\mathrm{p}}$ as function of normalized time $T \equiv I_{p} t /\left(C_{1} V_{p}\right)$ with normalized drive current slope $A \equiv C_{1} V_{p} k / I_{p}^{2}=0.01,0.02,0.05,0.1$ are shown in Fig. 4 through Fig. 9 for $\mathrm{C}_{2} / \mathrm{C}_{1}=0.02,0.05,0.1,0.2,0.5,1.0$ and for $\mathrm{L} \equiv \mathrm{I}_{\mathrm{p}}^{2} \mathrm{~L}_{1} /\left(\mathrm{V}_{\mathrm{p}}^{2} \mathrm{C}_{1}\right)=0.1,0.2$ $0.5,1.0,-2.0,5.0$.

As an example, if a fast tunnel-diode with an $I_{p}=10 \mathrm{~mA}, V_{p}=100 \mathrm{mV}$, $\mathrm{C}_{2}=0.5 \mathrm{pF} ;$ and $\mathrm{L}_{1}=0.5 \mathrm{nH}$ is used in a circuit with $\mathrm{C}_{1}=10 \mathrm{pF}$ (mostly external to the diode) and with $\mathrm{k}=5 \mathrm{~mA} / \mathrm{nsec}$, then $\mathrm{C}_{2} / \mathrm{C}_{1}=0.05$, $A \equiv C_{1} V_{p} k / I_{p}^{2}=0.05$, and $L \equiv I_{p}^{2} L_{1} /\left(V_{p}^{2} C_{1}\right)=0.5$, and the resulting transient is that of Fig. 5(c) with $A=0.05$ and a time scale of $t / T=100$ psec. It is seen that there is a ringing on the voltage rise, impeding subsequent timing operations. If, however, $\mathrm{C}_{1}$ is reduced to $2.5 \mathrm{pF}$, then $\mathrm{C}_{2} / \mathrm{C}_{1}=0.2$, $\mathrm{A}=0.0125$, and $\mathrm{L}=2$, and the transient of Fig. $7(\mathrm{e})$ with $\mathrm{A}=0.0125$ and a time scale of $t / T=25$ psec results. This has a smooth initial rise, and also a subsequent ringing which is usually preferable to the ringing on the rise. If capacitance $\mathrm{C}_{1}$ cannot be reduced, ringing on the rise can be eliminated by increasing $\mathrm{C}_{2}$, i.e., by the use of a "slower" tunnel-dinde. 


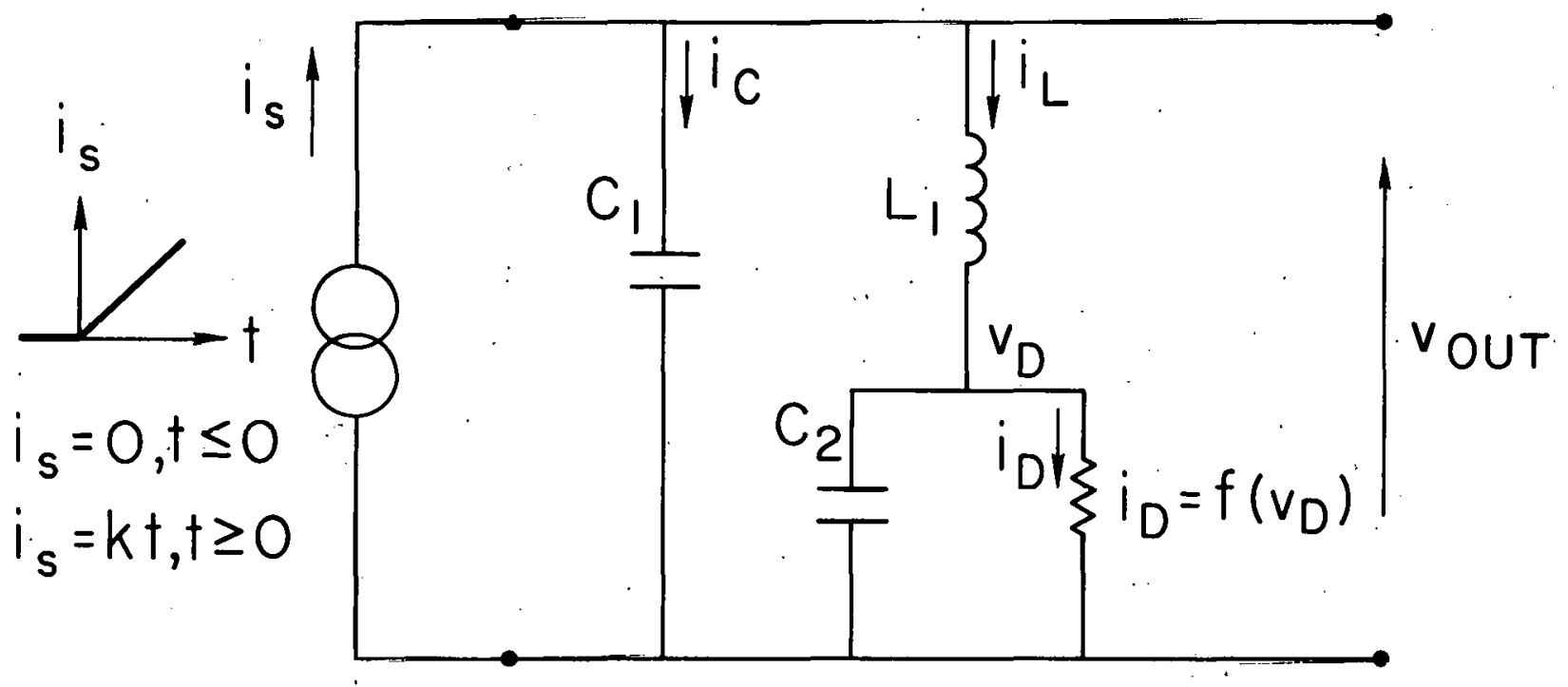

$1075 A$

FIG. 1--Tunnel-diode circuitry • 


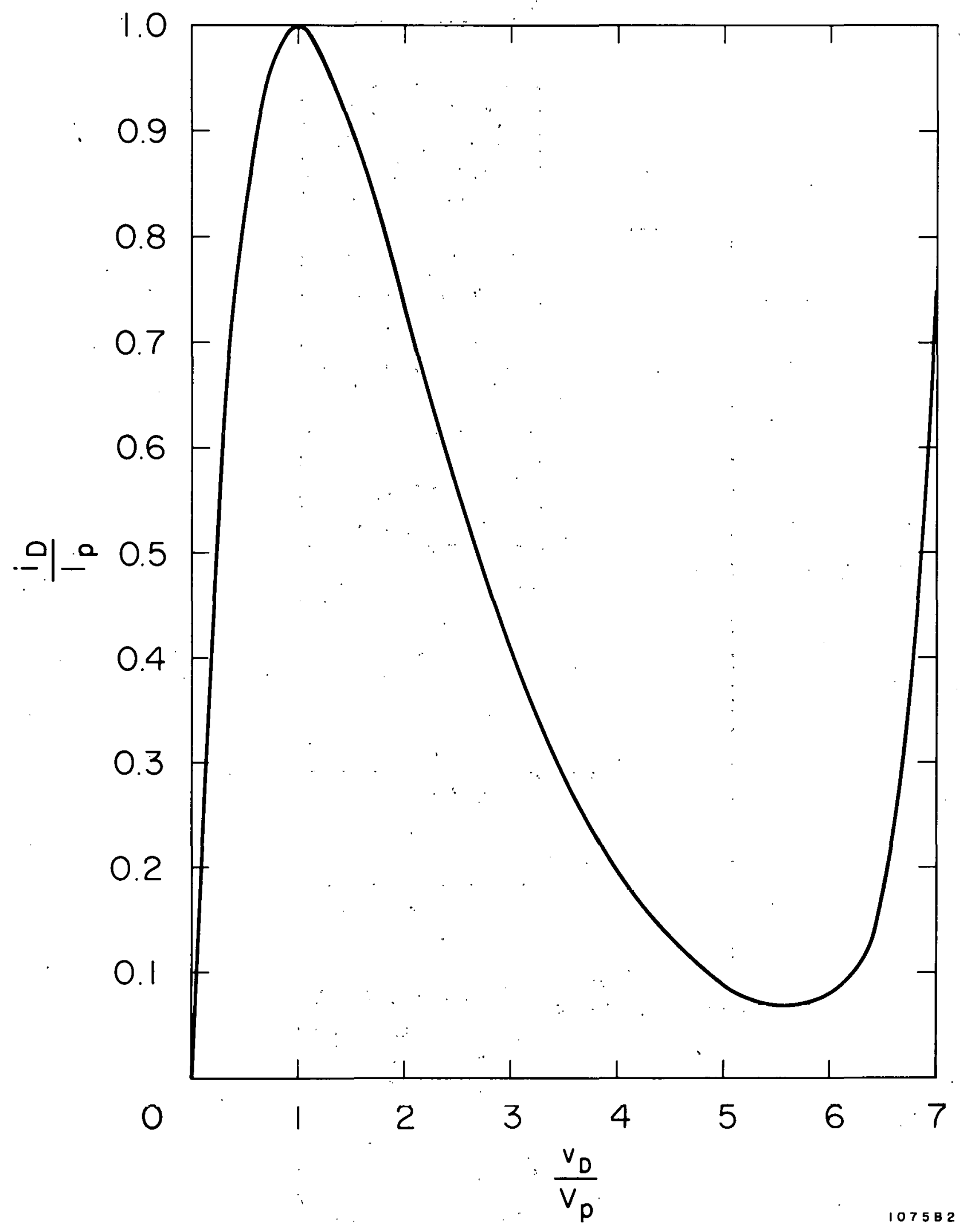

FIG. 2--Tunnel-diode dc current versus voltage characteristic. 


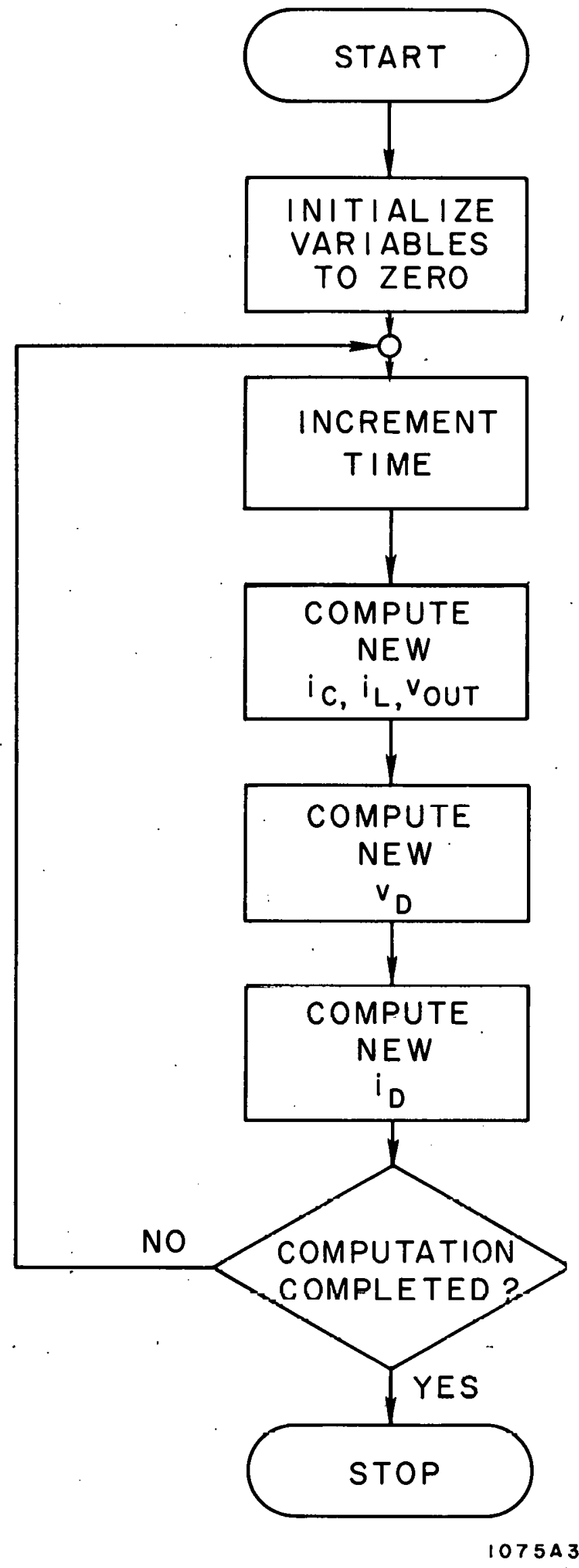

FIG. 3--Flow-chart of the computer program. 


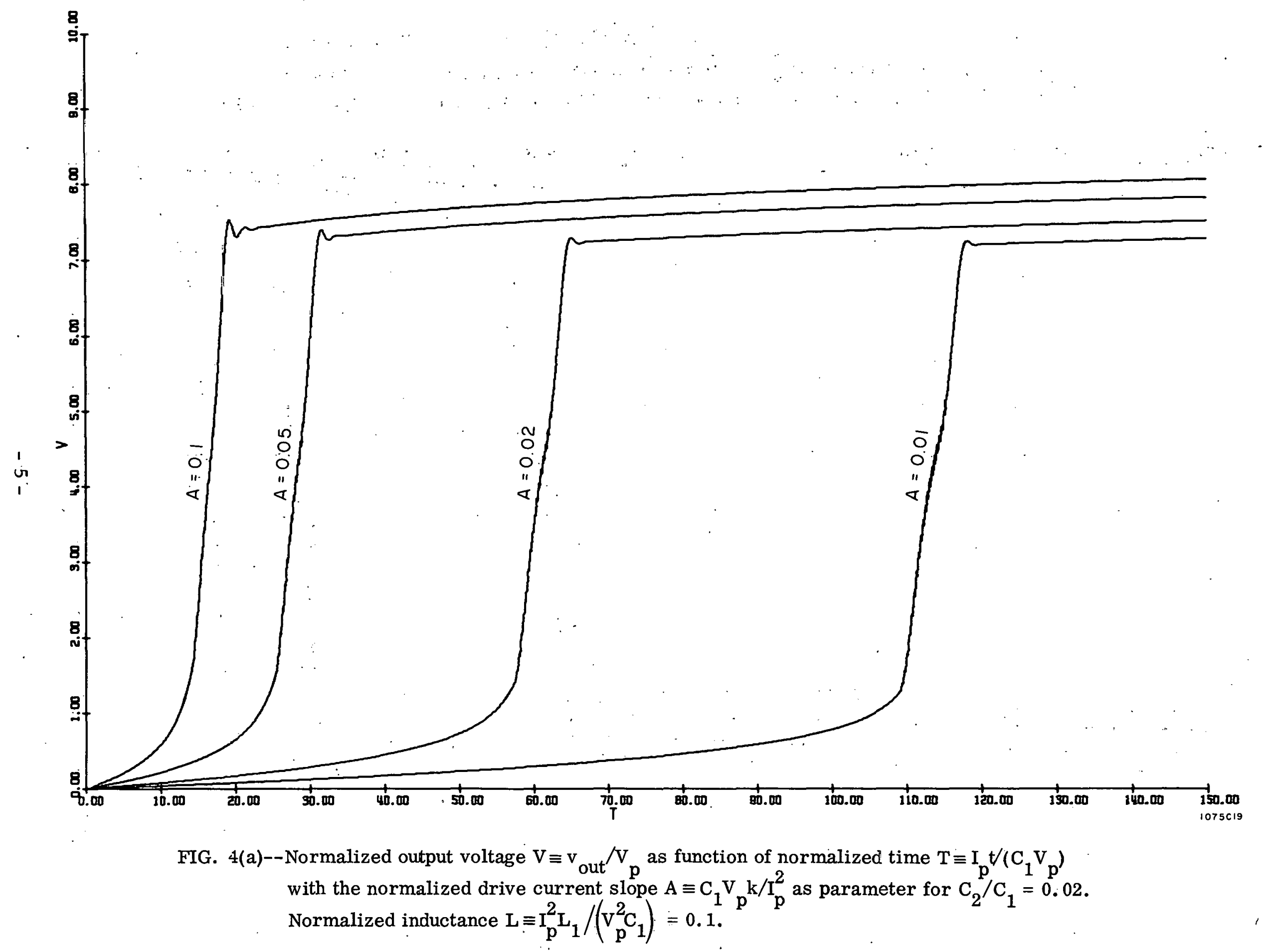




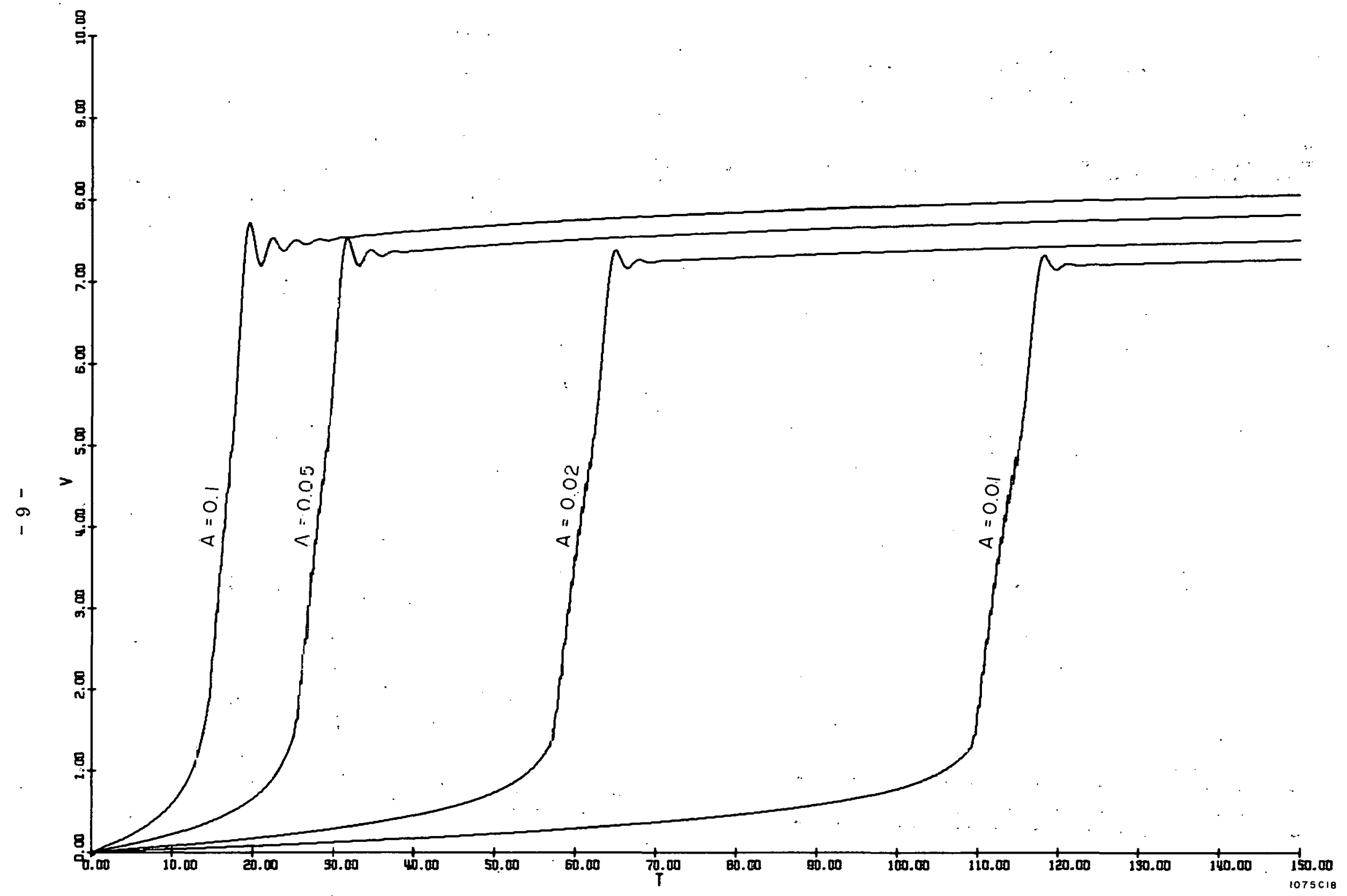

FIG. $4\left(\right.$ b)--Normalized output voltage $V \equiv v_{\text {out }} / v_{p}$ as function of normalized time $T \equiv I_{p} t /\left(C_{1} V_{p}\right)$ with the normalized drive current slope $A \equiv C_{1} V_{p} k / r_{p}^{2}$ as parameter for $C_{2} / C_{1}=0.02$. Normalized inductance $\mathrm{L} \equiv \mathrm{I}_{\mathrm{p}}^{2} \mathrm{~L}_{1} /\left(\mathrm{v}_{\mathrm{p}}^{2} \mathrm{C}_{1}\right)=0.2$. 


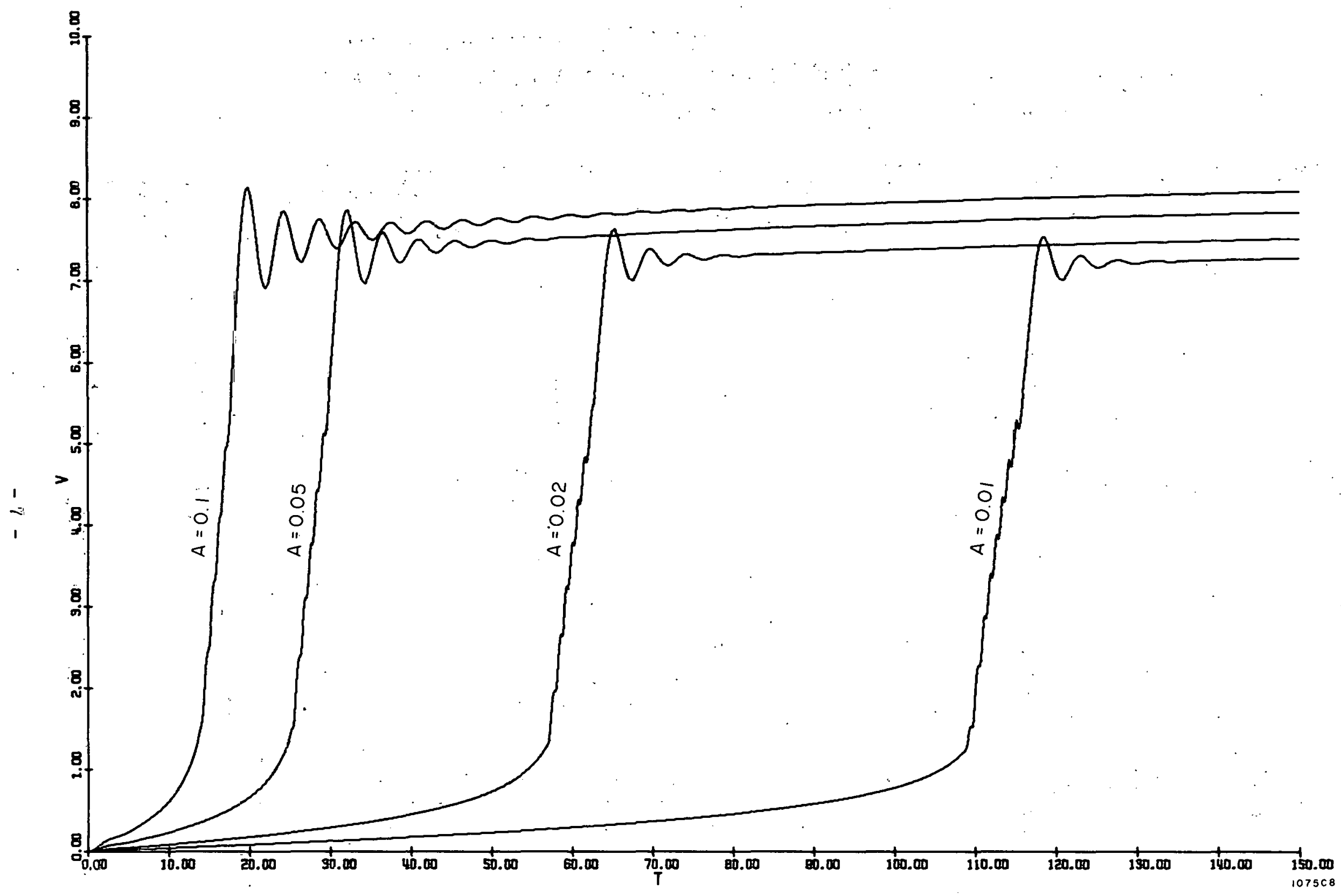

FIG. $\leq(c)--$ Normalized output voltage $V \equiv v_{\text {out }} / v_{p}$ as function of normalized time $T \equiv I_{p} t /\left(C_{1} V_{p}\right)$ with the normalized drive current slope $A \equiv C_{1} V_{p} k / I_{p}^{2}$ as parameter for $C_{2} / C_{1}=0.02$. Normalized inductance $\mathrm{L} \equiv \mathrm{I}_{\mathrm{p}}^{2} \mathrm{~L}_{1} /\left(\mathrm{V}_{\mathrm{p}}^{2} \mathrm{C}_{1}\right)=0.5$. 


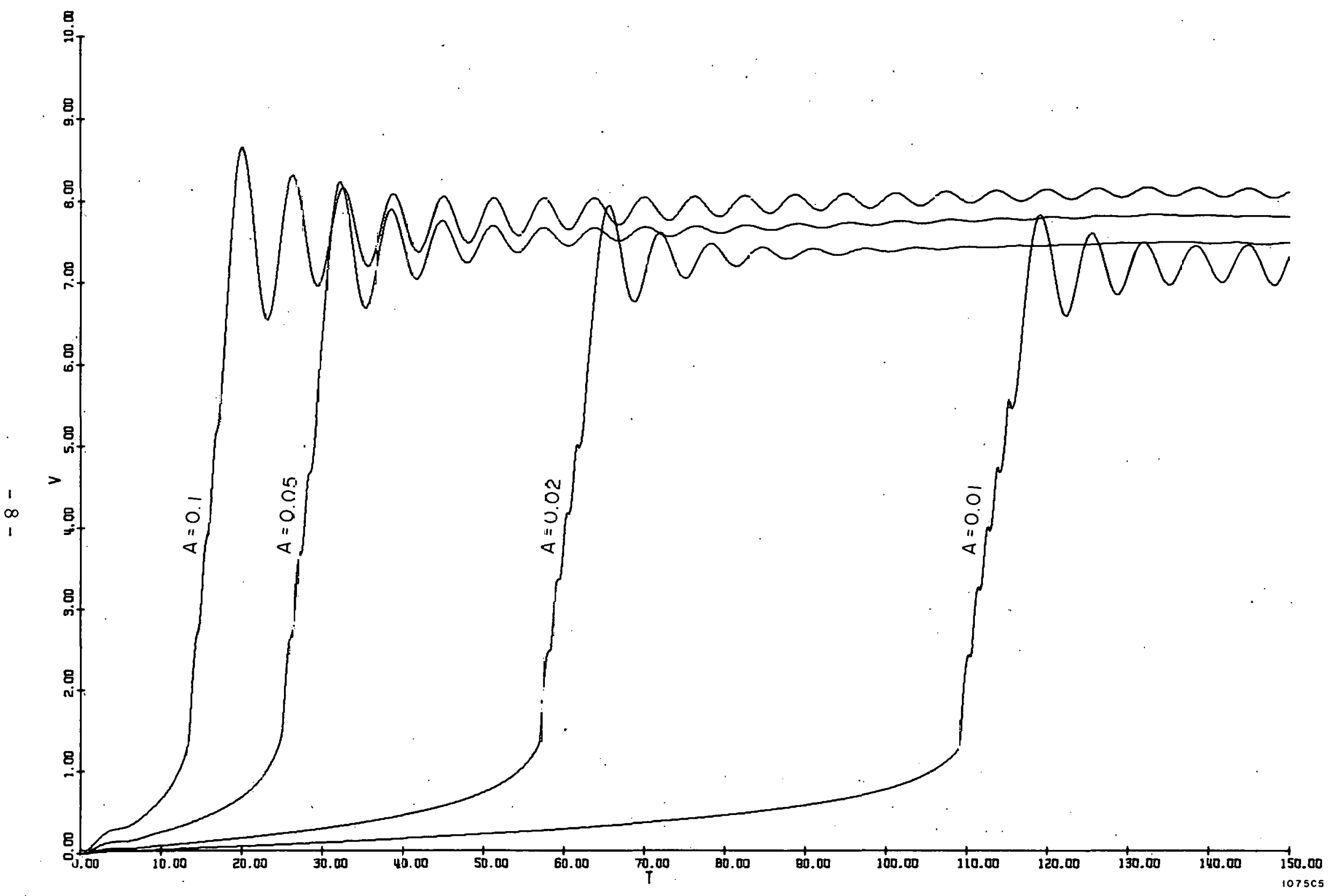

FIG. 4(d)--Normalized output voltage $V \equiv v_{\text {out }} / \sim_{p}$ as function of normalized time $T \equiv I_{p} t /\left(C_{1} V_{p}\right)$ with the normalized drive current slope $A \equiv C_{1} V_{p} k / I_{p}^{2}$ as parameter for $C_{2} / C_{1}=0.02$. Normalized inductance $\mathrm{L} \equiv \mathrm{I}_{\mathrm{p}}^{2} \mathrm{~L}_{1} /\left(\mathrm{v}_{\mathrm{p}}^{2} \mathrm{C}_{1}\right)=1.0$. 


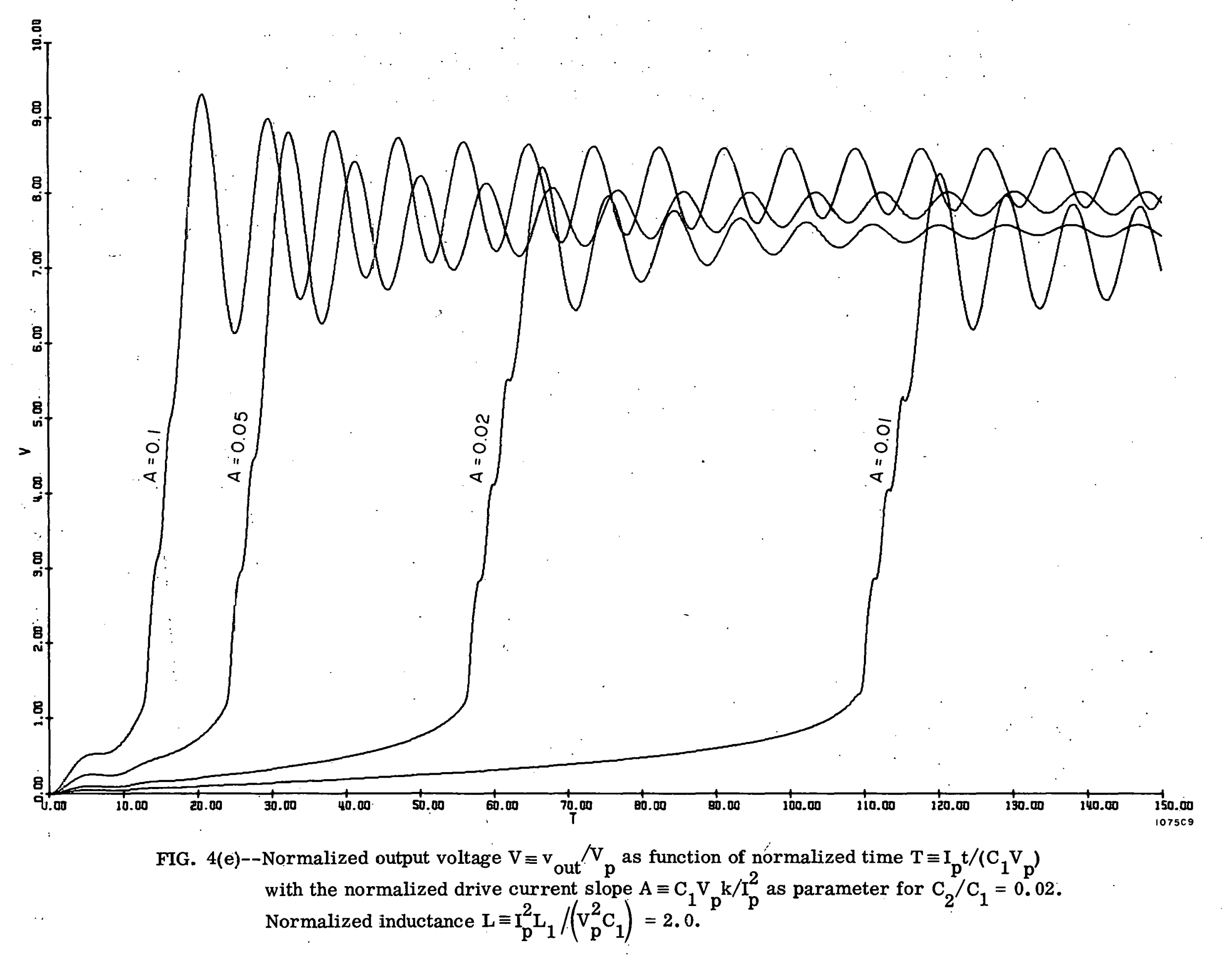




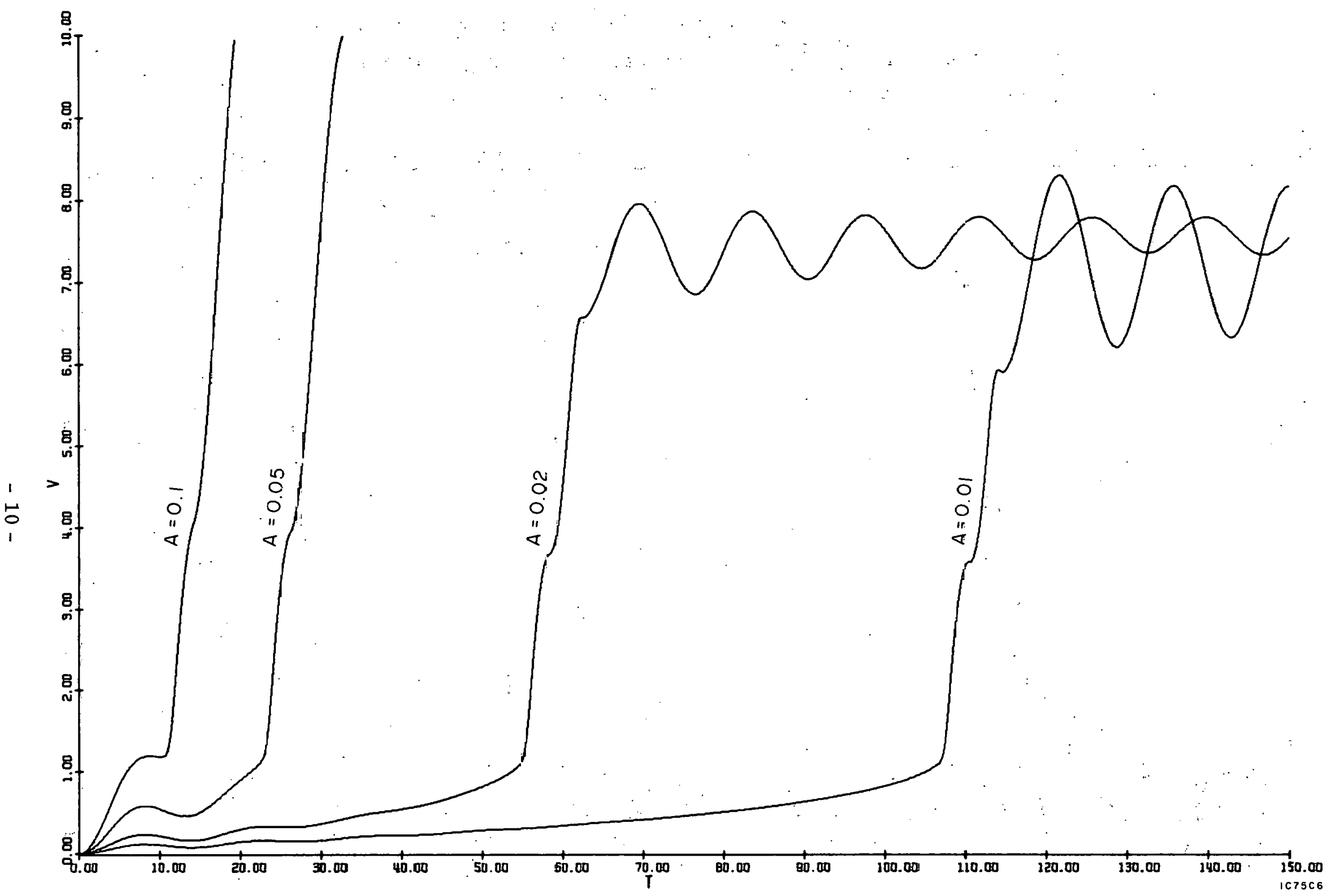

FIG. $4(f)-$ Normalized output voltage $V \equiv v_{\text {out }} / v_{p}$ as function of normalized time $T \equiv I_{p} t /\left(C_{1} V_{p}\right)$ with the normalized drive current slope $A=C_{1} V_{p} k / I_{p}^{2}$ as parameter for $C_{2} / C_{1}=0.02$. Normalized inductance $\mathrm{L} \equiv \mathrm{I}_{\mathrm{p}}^{2} \mathrm{~L}_{1} /\left(\mathrm{V}_{\mathrm{p}}^{2} \mathrm{C}_{1}\right)=5.0$. 


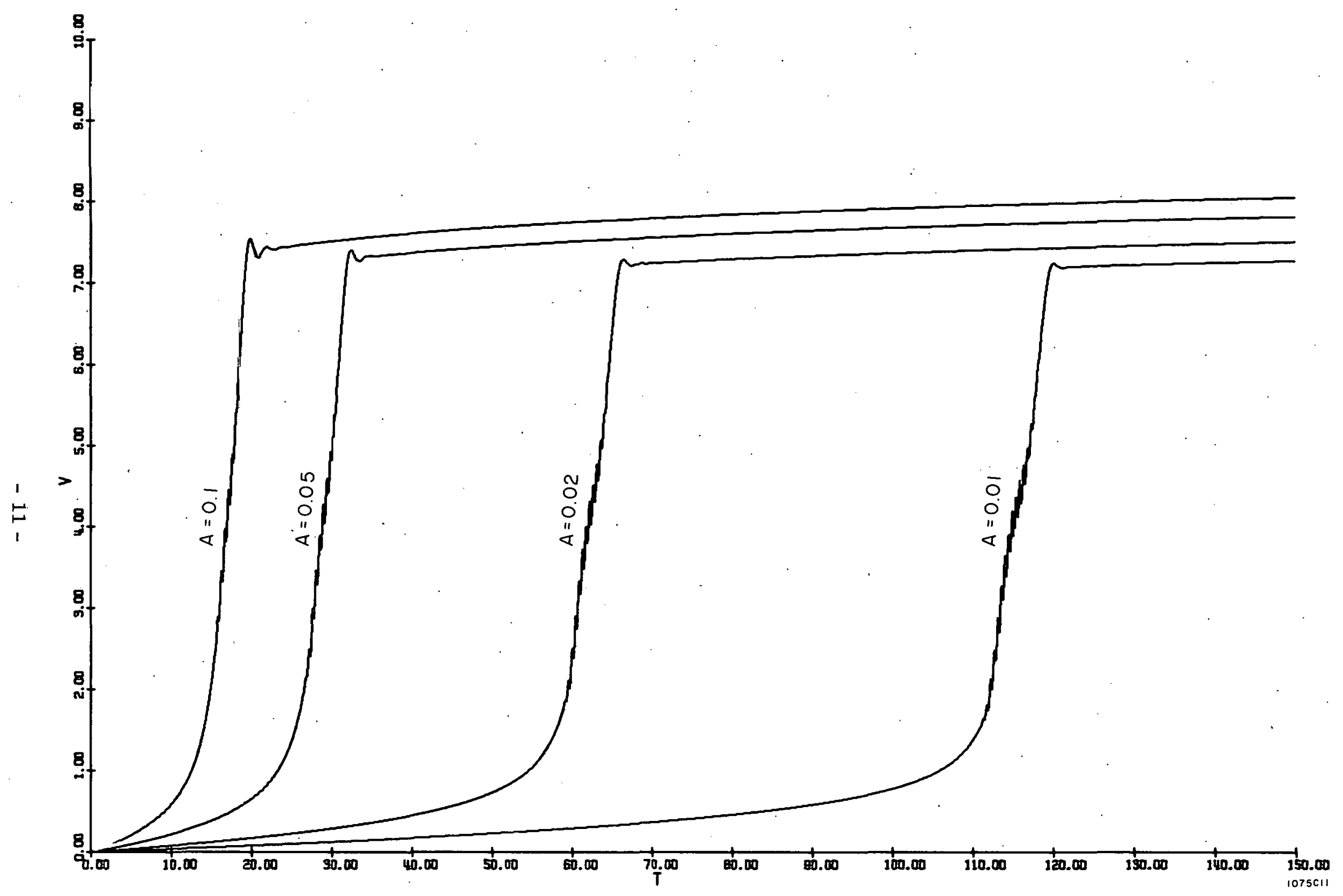

FIG. 5(a)--Normalized output voltage $V \equiv v_{\text {out }} / \mathrm{V}_{p}$ as function of normalized time $T \equiv \mathrm{I}_{\mathrm{p}} \mathrm{t} /\left(\mathrm{C}_{1} \mathrm{~V}_{\mathrm{p}}\right)$ with the normalized drive current slope $A \equiv C_{1} V_{p} k / I_{p}^{2}$ as parameter for $C_{2} / C_{1}=0.05$. Normalized inductance $\mathrm{L} \equiv \mathrm{I}_{\mathrm{p}}^{2} \mathrm{~L}_{1} /\left(\mathrm{V}_{\mathrm{p}}^{2} \mathrm{C}_{1}\right)=0.1$. 


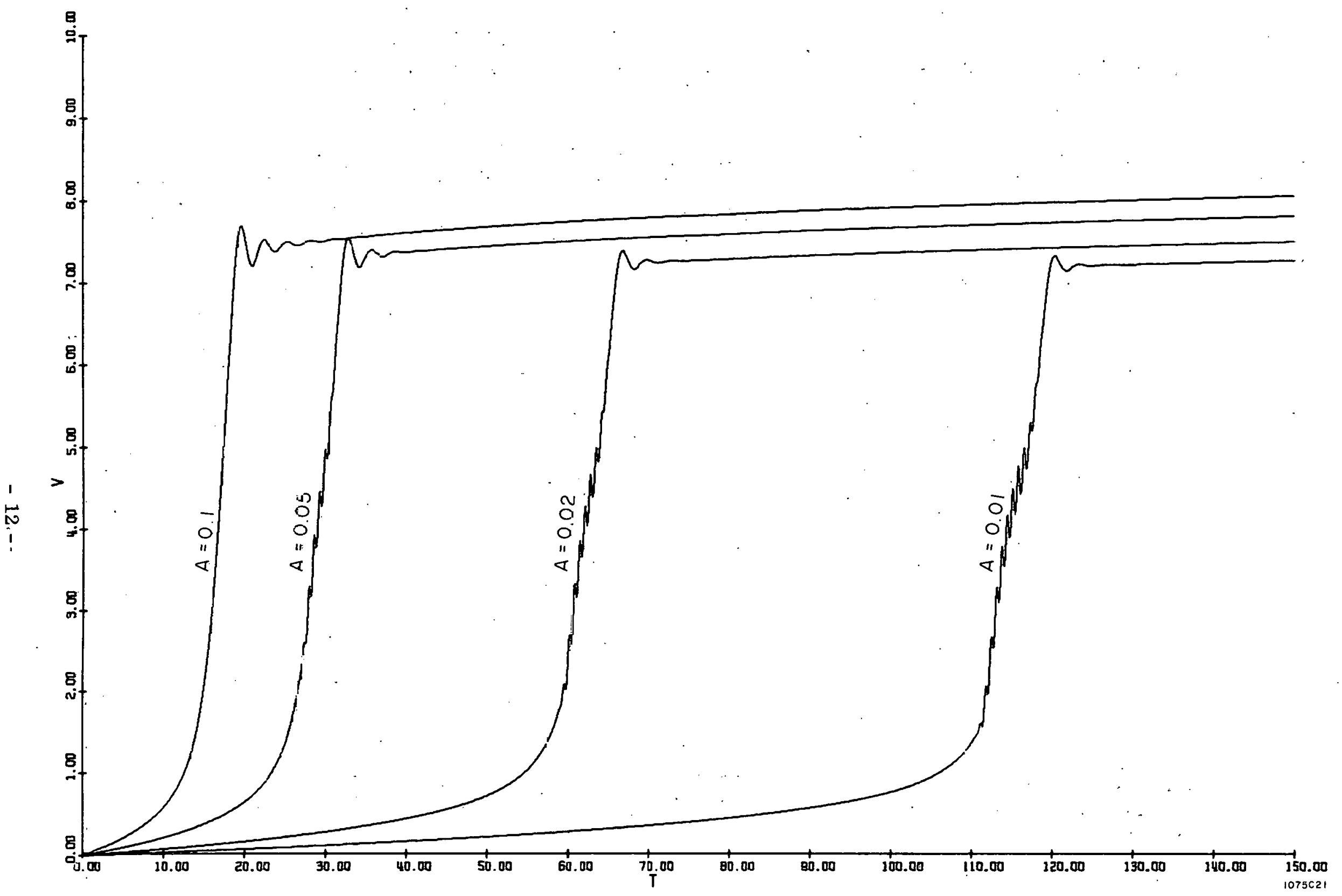

FIG. 5(b)--Normalized output voltage $V \equiv v_{\text {out }} / \mathrm{v}_{\mathrm{p}}$ as function of normalized time $T \equiv \mathrm{I}_{\mathrm{p}} \mathrm{t} /\left(\mathrm{C}_{1} \mathrm{~V}_{\mathrm{p}}\right)$ with the normalized drive current slope $A \equiv C_{1} V_{p} k / I_{p}^{2}$ as parameter for $C_{2} / C_{1}=0.05$. Normalized inductance $\mathrm{L} \equiv \mathrm{I}_{\mathrm{p}}^{2} \mathrm{~L}_{1} /\left(\mathrm{V}_{\mathrm{p}}^{2} \mathrm{C}_{1}\right)=0.2$. 


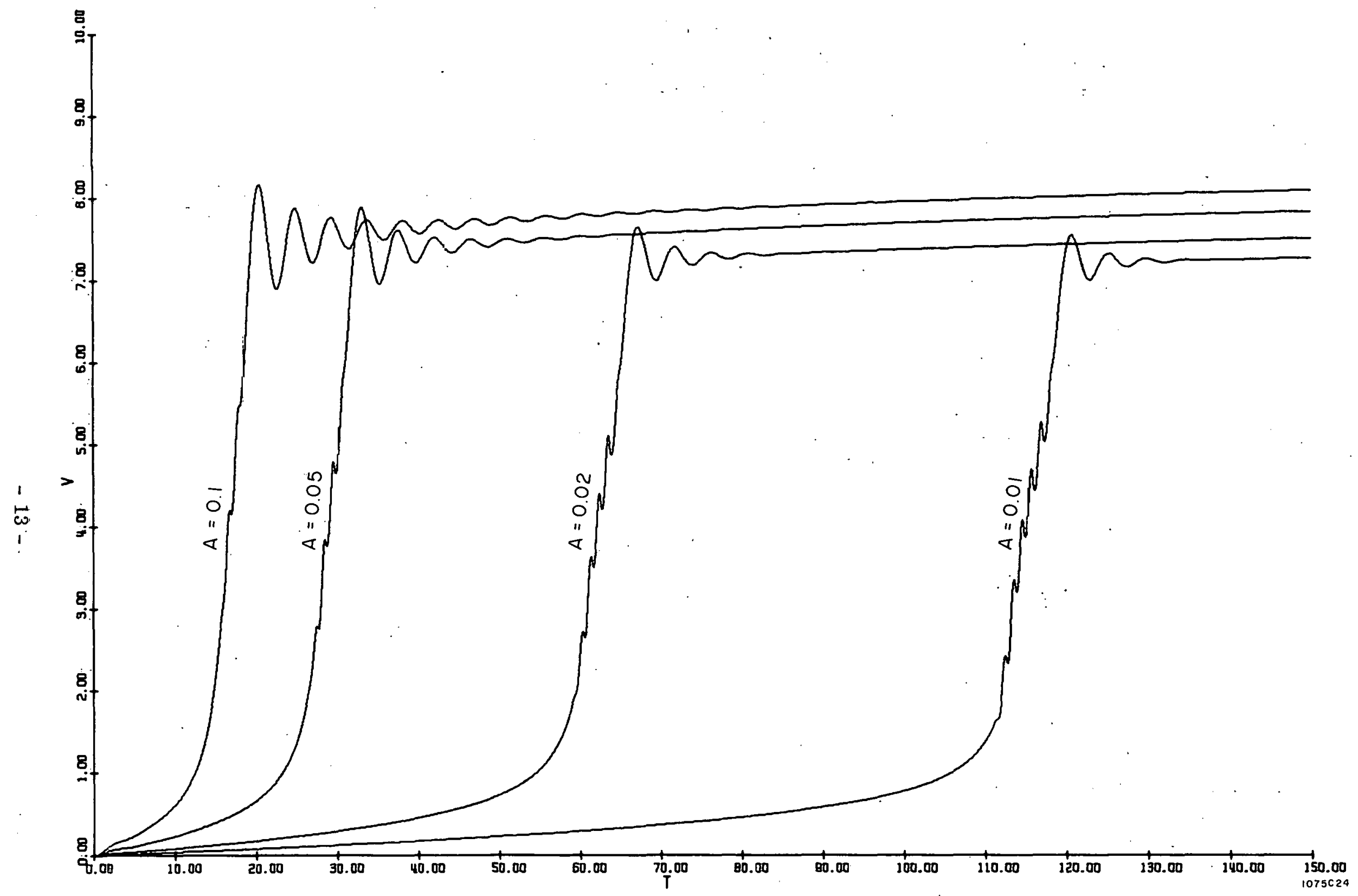

FIG. $5(c)$--Normalized output voltage $V \equiv v_{\text {out }} / V_{p}$ as function of normalized time $T \equiv I_{p} t /\left(C_{1} V_{p}\right)$ with the normalized drive current slope $A \equiv C_{1} V_{p} k / I_{p}^{2}$ as parameter for $C_{2} / C_{1}=0.05$. Normalized inductance $\mathrm{L} \equiv \mathrm{I}_{\mathrm{p}}^{2} \mathrm{~L}_{1} /\left(\mathrm{V}_{\mathrm{p}}^{2} \mathrm{C}_{1}\right)=0.5$. 


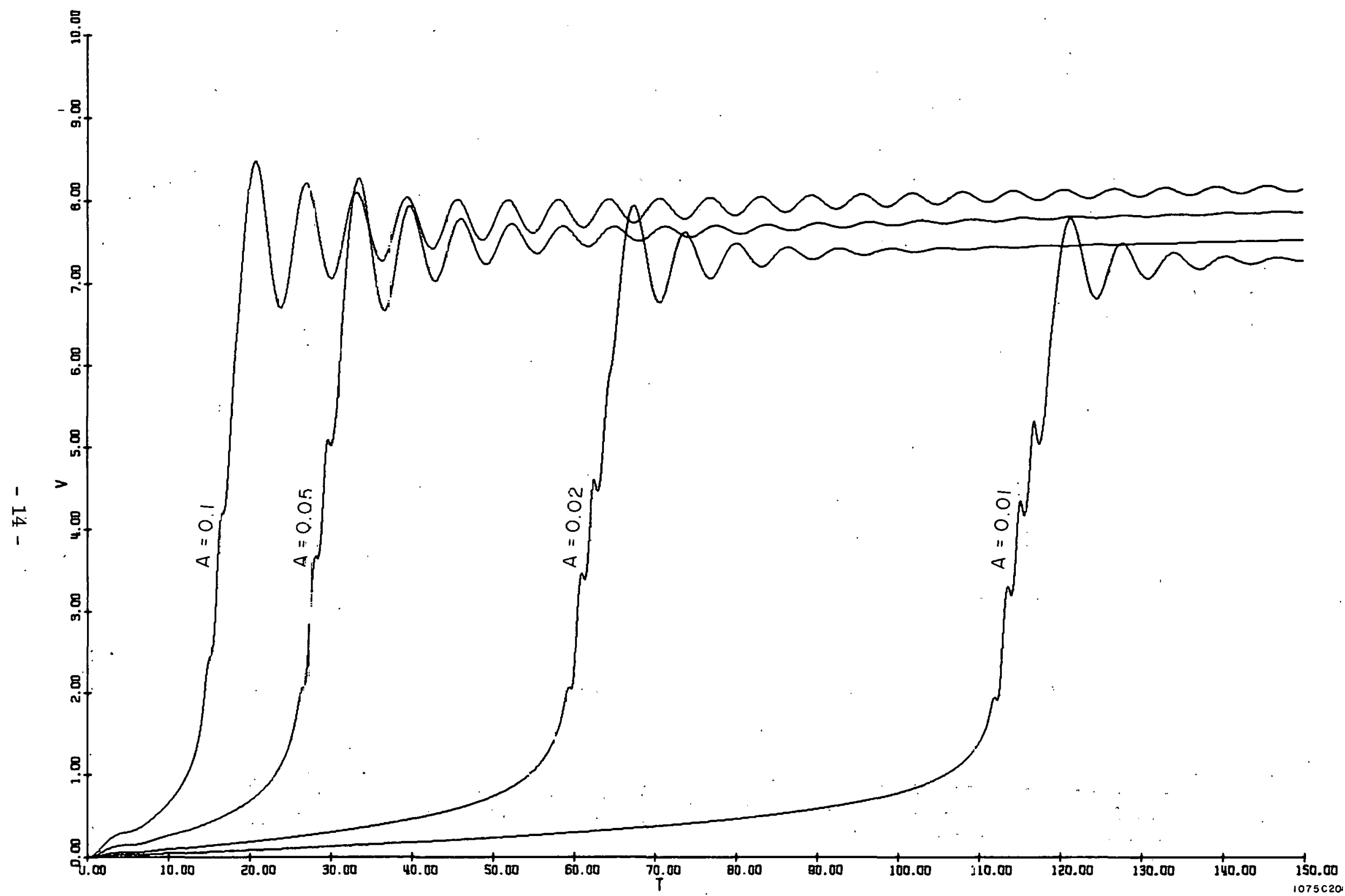

FIG. $5(d)--$ Normalized output voltage $V \equiv v_{\text {out }} / V_{p}$ as function of normalized time $T \equiv I_{p} t /\left(C_{1} V_{p}\right)$ with the normalized drive current slope $A \equiv C_{1} V_{p} k / I_{p}^{2}$ as parameter for $C_{2} / C_{1}=0.05$. Normalized inductance $\mathrm{L} \equiv \mathrm{I}_{\mathrm{p}}^{2} \mathrm{~L}_{1} /\left(\mathrm{v}_{\mathrm{p}}^{2} \mathrm{C}_{1}\right)=1.0$. 


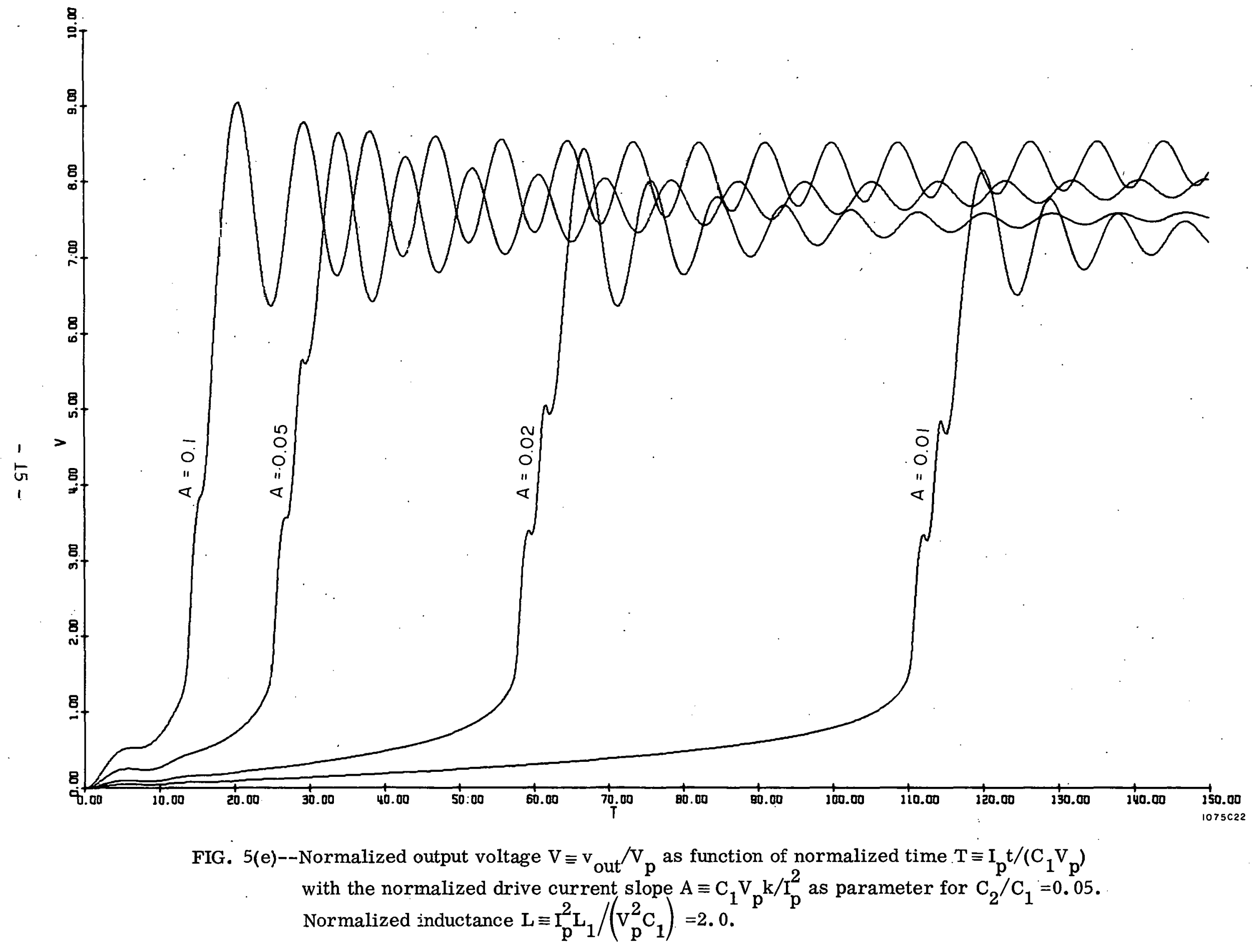




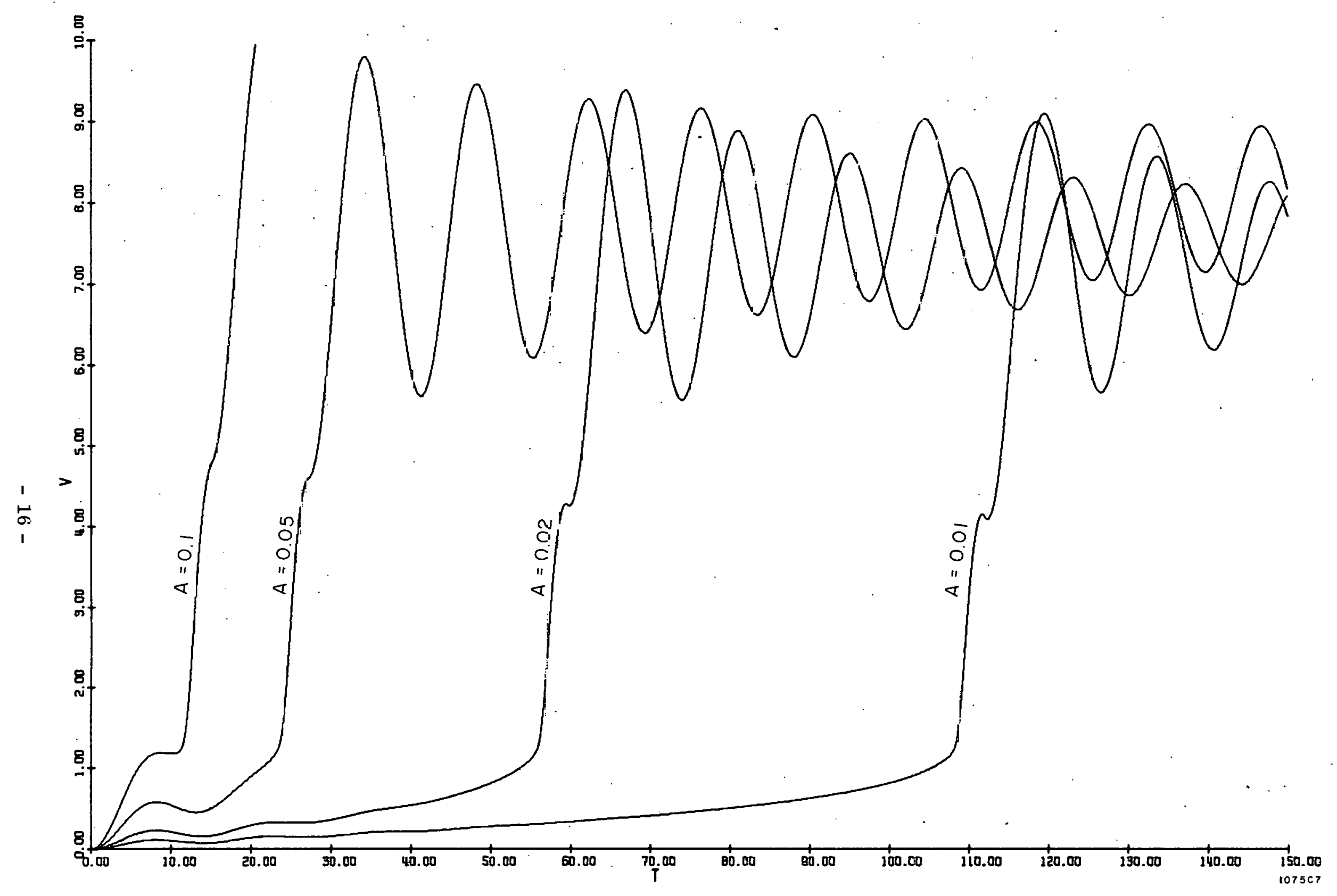

FIG. $5(f)$--Normalized output voltage $V \equiv v_{\text {out }} / \mathrm{V}_{p}$ as function of normalized time $T \equiv I_{p} t^{\prime}\left(C_{1} V_{p}\right)$ with the normalized drive current slope $A \equiv C_{1} V_{p} k / I_{p}^{2}$ as parameter for $C_{2} / C_{1}=0.05$. Normalized inductance $\mathrm{L} \equiv \mathrm{I}_{\mathrm{p}}^{2} \mathrm{~L}_{1} /\left(\mathrm{V}_{\mathrm{p}}^{2} \mathrm{C}_{1}\right)=5.0$. 


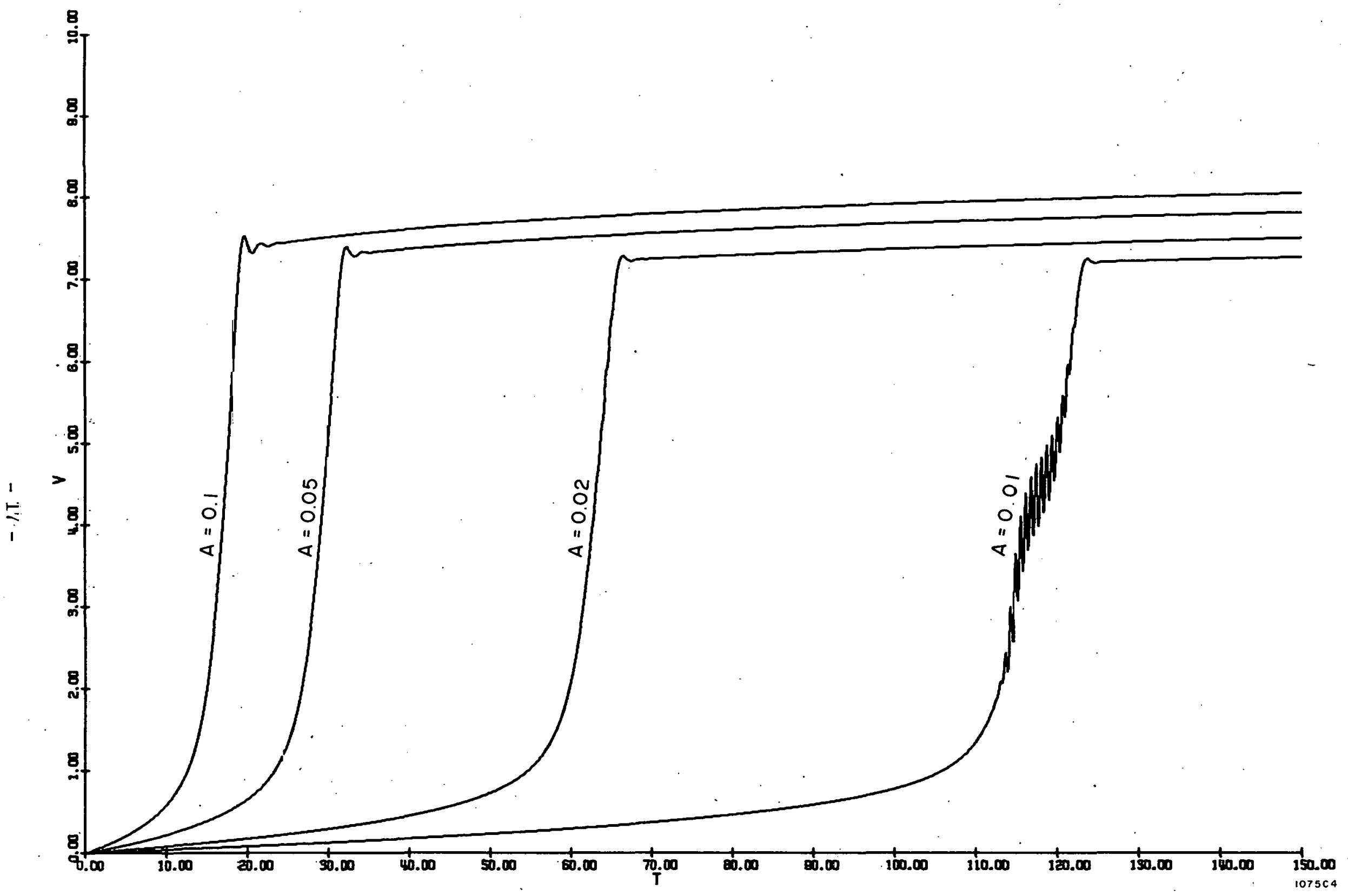

FIG. 6(a)--Normalized output voltage $V \equiv v_{\text {out }} / \mathrm{V}_{p}$ as function of normalized time $T \equiv I_{p} t /\left(C_{1} V_{p}\right)$ with the normalized drive current slope $A \equiv C_{1} V_{p} k / I_{p}^{2}$ as parameter for $C_{2} / C_{1}=0.1$. Normalized inductance $\mathrm{L} \equiv \mathrm{I}_{\mathrm{p}}^{2} \mathrm{~L}_{1} /\left(\mathrm{V}_{\mathrm{p}}^{2} \mathrm{C}_{1}\right)=0.1$. 


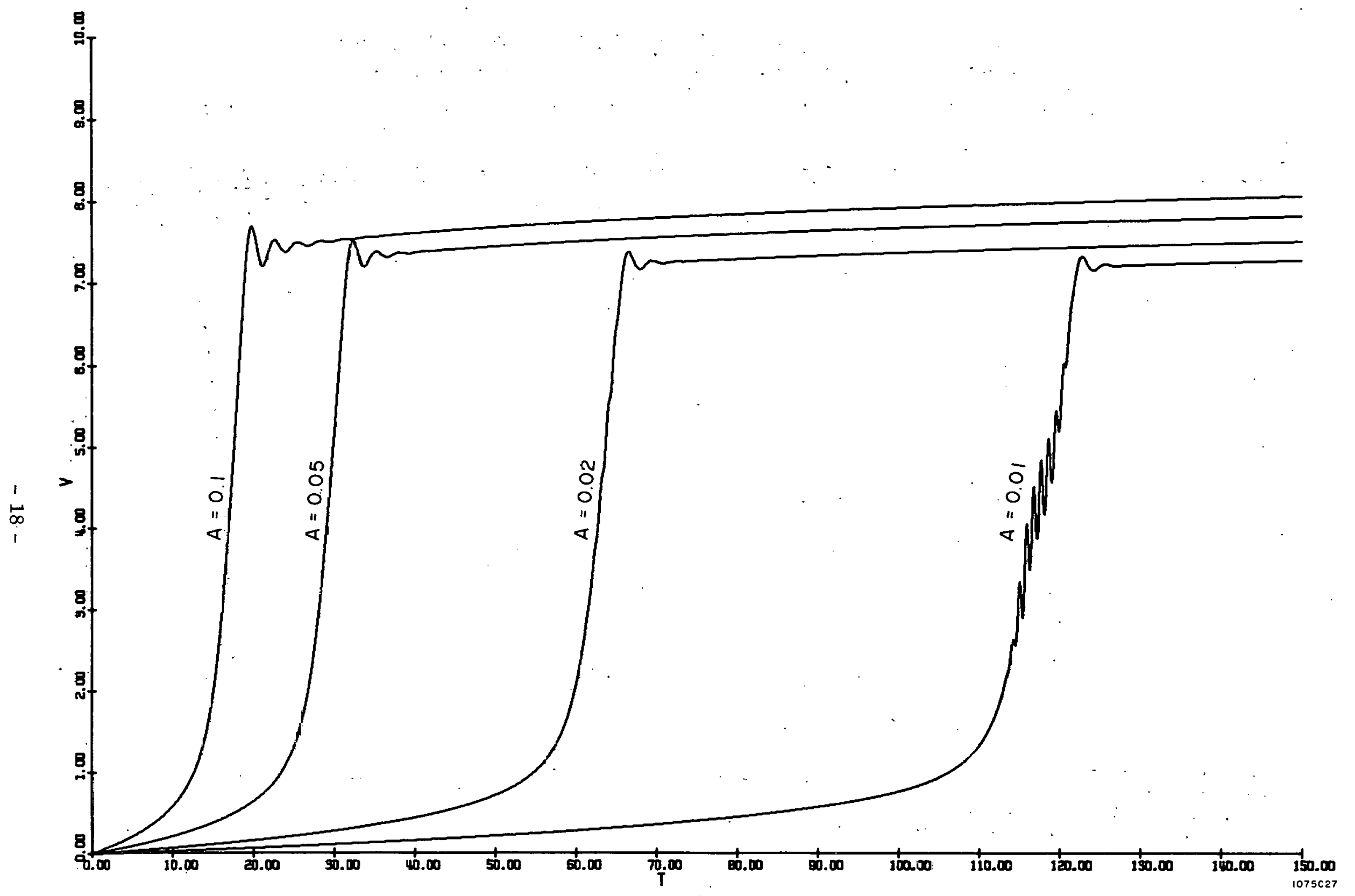

FIG. $B(b)--$ Normalized output voltage $V \equiv v_{\text {out }} / v_{p}$ as function of normalized time $T \equiv I_{p} t /\left(C_{1} V_{p}\right)$ with the normalized drive current slope $A \equiv C_{1} V_{p} k / r_{p}^{2}$ as parameter for $C_{2} / C_{1}=0.1$. Normalized inductance $L \equiv I_{p}^{2} L_{1} /\left(v_{p}^{2} C_{1}\right)=0.2$. 


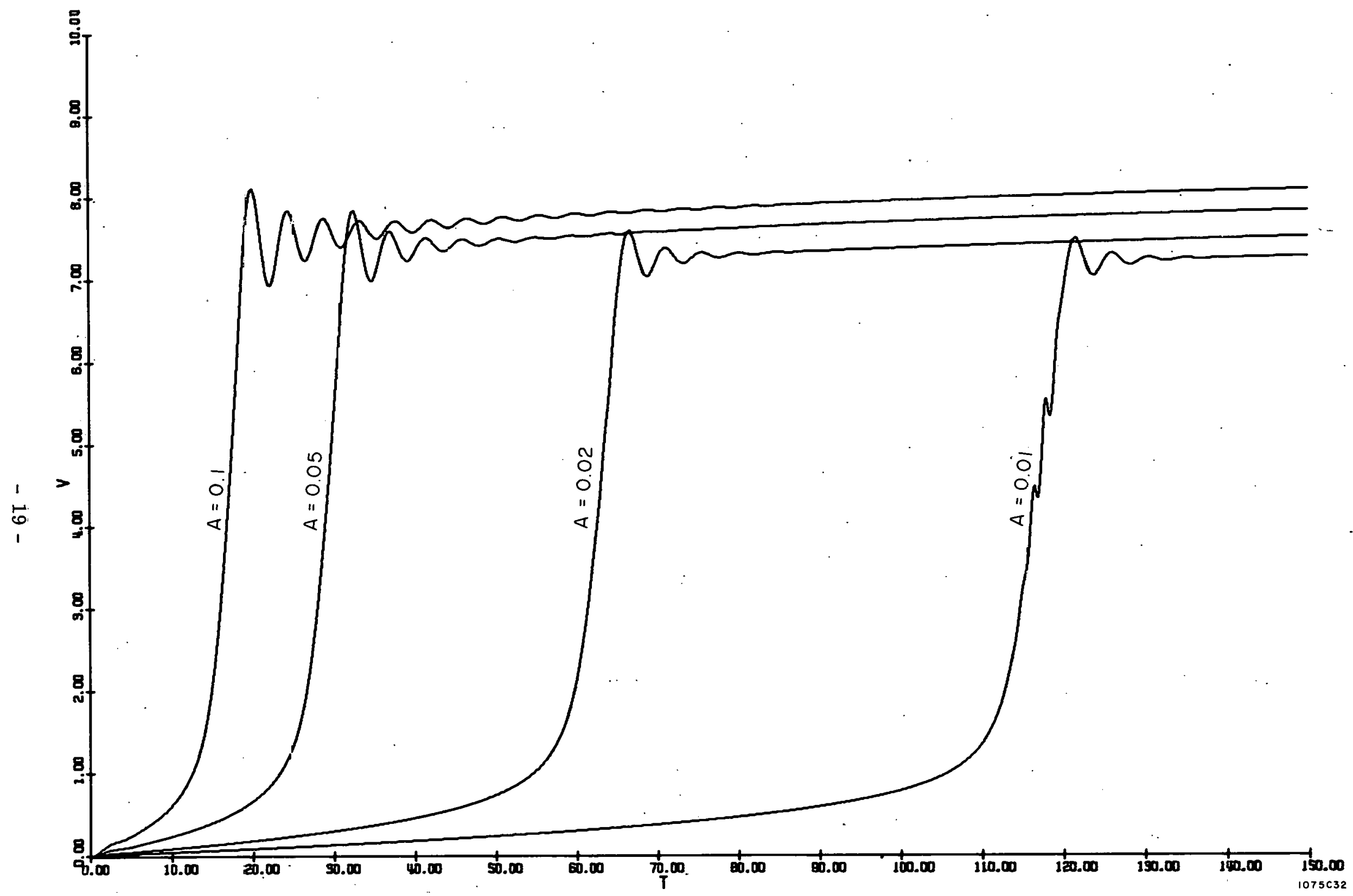

FIG. 6(c)--Normalized output voltage $V \equiv v_{\text {out }} / V_{p}$ as function of normalized time $T \equiv I_{p} t /\left(C_{1} V_{p}\right)$ with the normalized drive current slope $A \equiv C_{1} V_{p} k / I_{p}^{2}$ as parameter for $C_{2} / C_{1}=0.1$. Normalized inductance $\mathrm{L} \equiv \mathrm{I}_{\mathrm{p}}^{2} \mathrm{~L}_{1} /\left(\mathrm{V}_{\mathrm{p}}^{2} \mathrm{C}_{1}\right)=0.5$. 


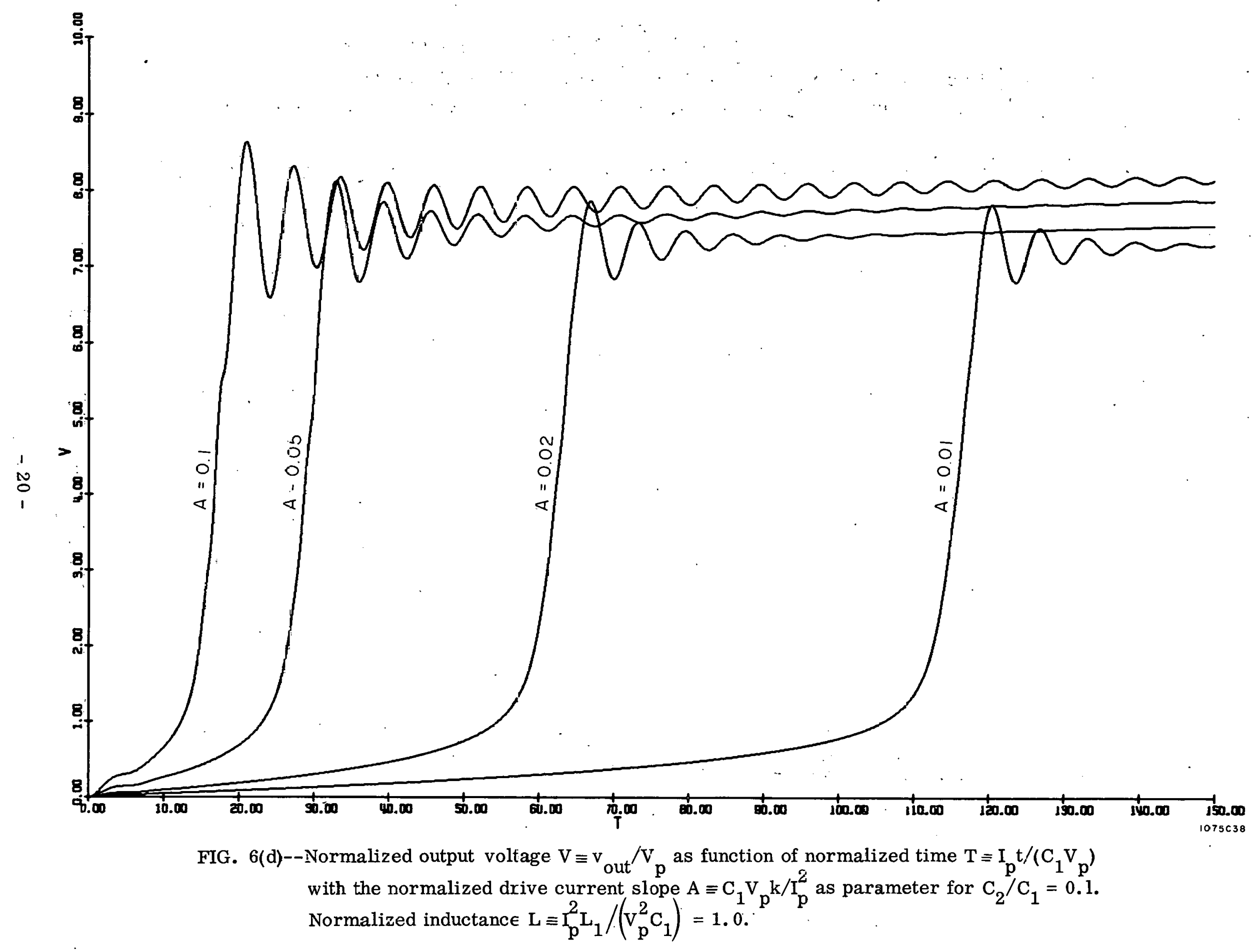




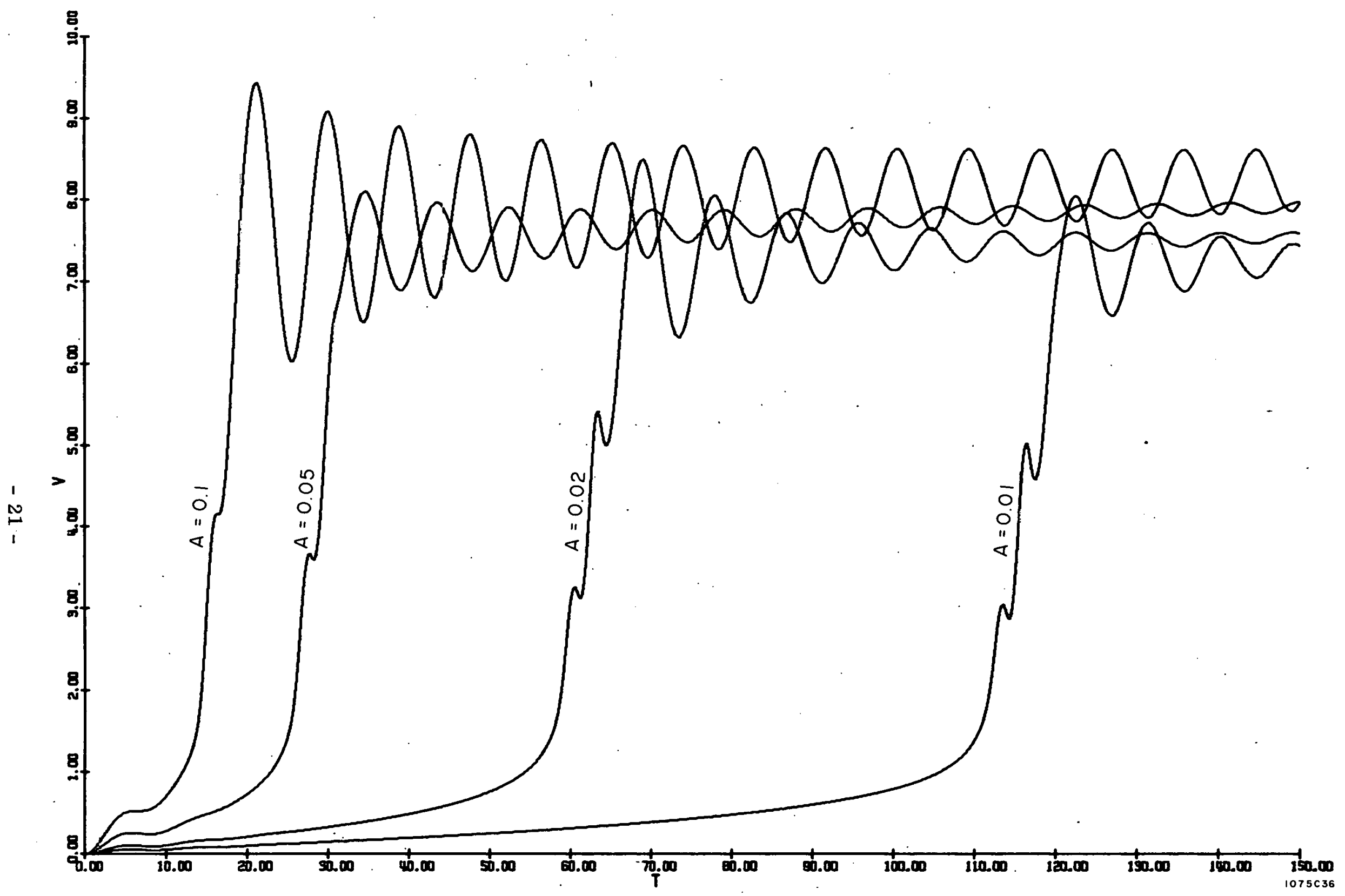

FIG. 6(e)--Normalized output voltage $V \equiv v_{\text {out }} / V_{p}$ as function of normalized time $T \equiv I_{p} t /\left(C_{1} V_{p}\right)$ with the normalized drive current slope $A \equiv C_{1} V_{p} k / I_{p}^{2}$ as parameter for $C_{2} / C_{1}=0$. 1 . Normalized inductance $\mathrm{L} \equiv \mathrm{I}_{\mathrm{p}}^{2} \mathrm{~L}_{1},\left(\mathrm{v}_{\mathrm{p}}^{2} \mathrm{C}_{1}\right)=2.0$. 


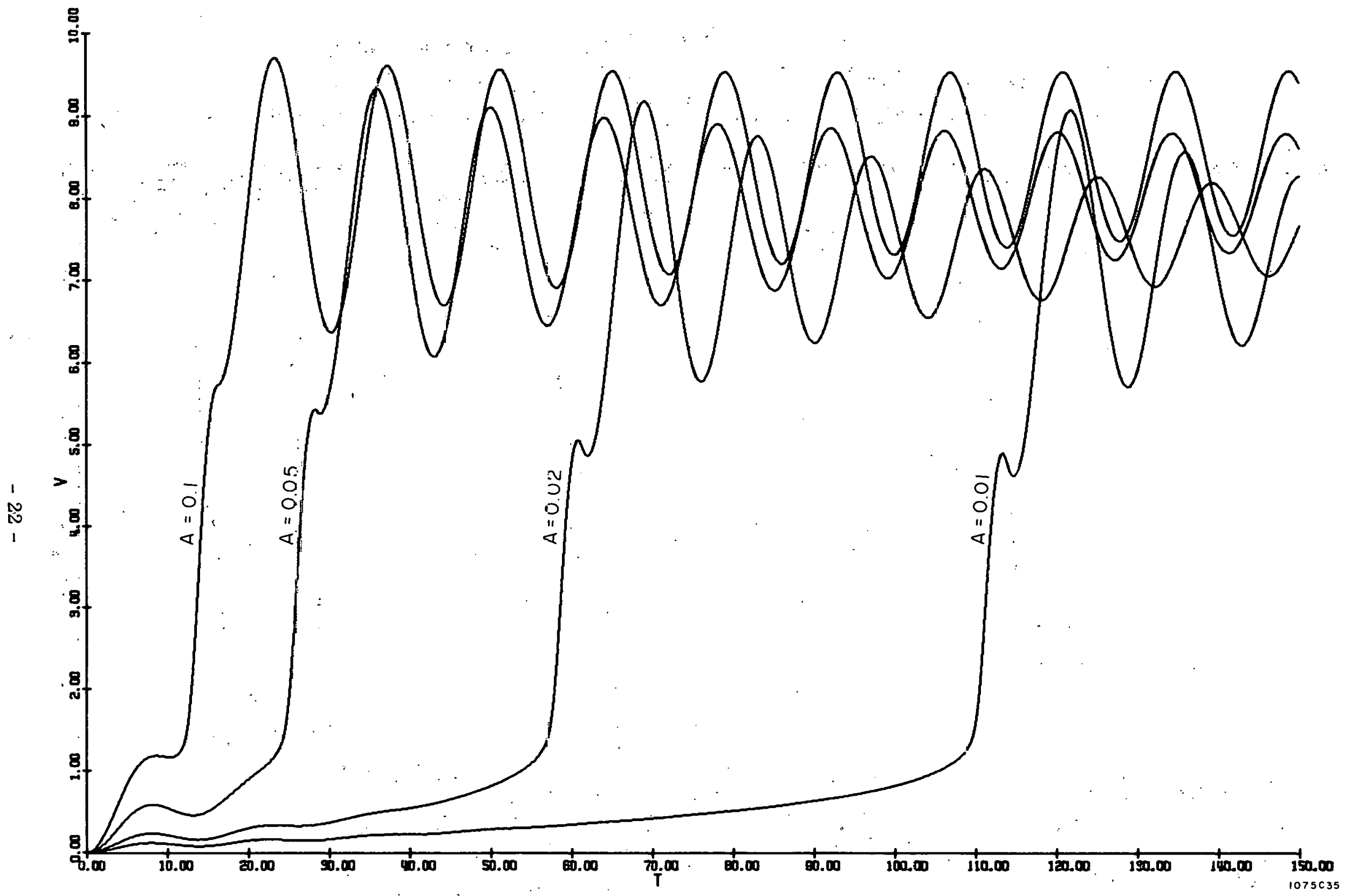

FIG. 6(f)--Normalized output voltage $v \equiv v_{\text {out }}{ }^{\prime} v_{p}$ as function of normalized time $T \equiv I_{p} t /\left(C_{1} v_{p}\right)$ with the normalized drive current slope $A \equiv C_{1} V_{p} k / I_{p}^{2}$ as parameter for $C_{2} / C_{1}=0.1$. Normalized inductance $\mathrm{L} \equiv \mathrm{I}_{\mathrm{p}}^{2} \mathrm{~L}_{1} /\left(\mathrm{V}_{\mathrm{p}}^{2} \mathrm{C}_{1}\right)=5.0$. 


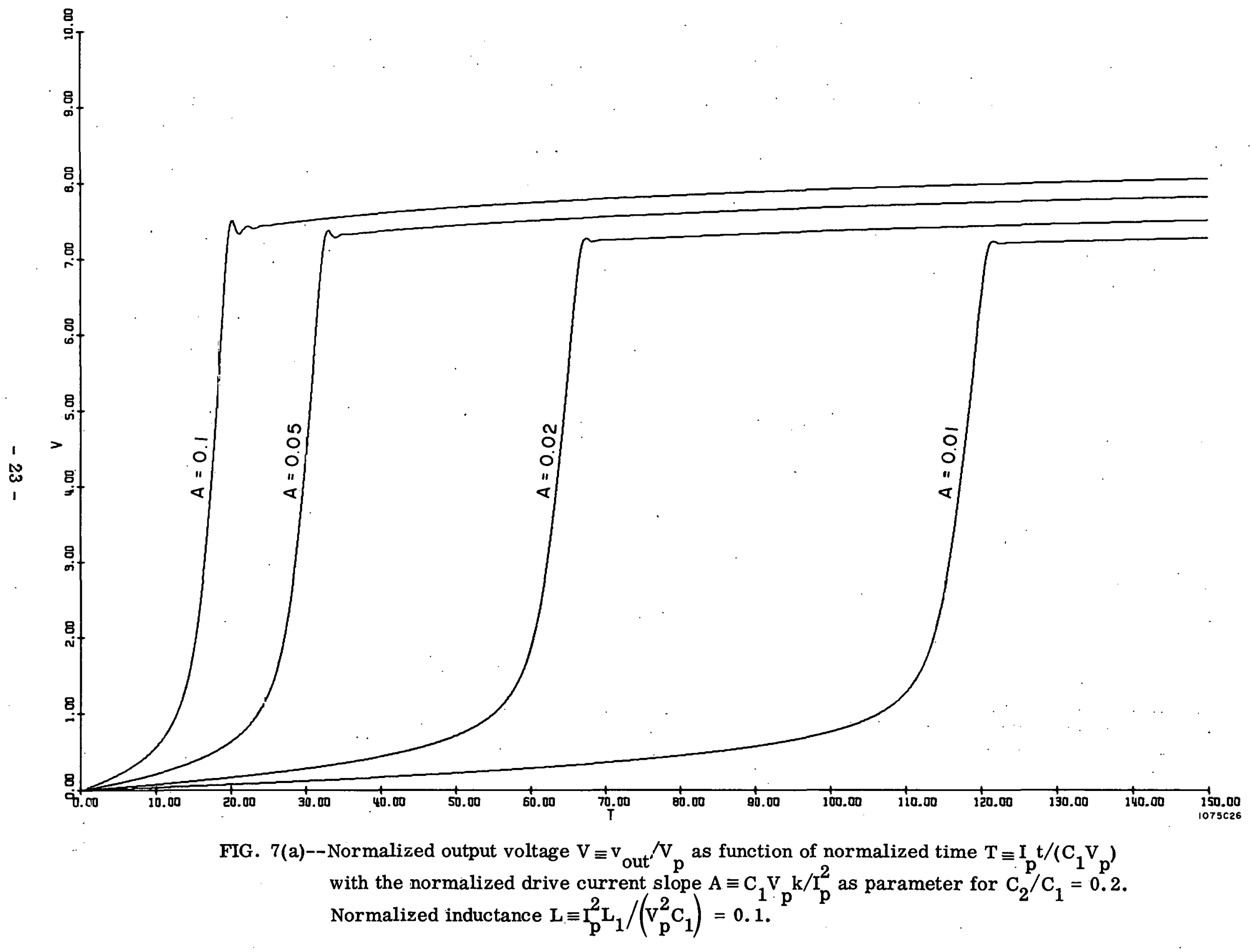




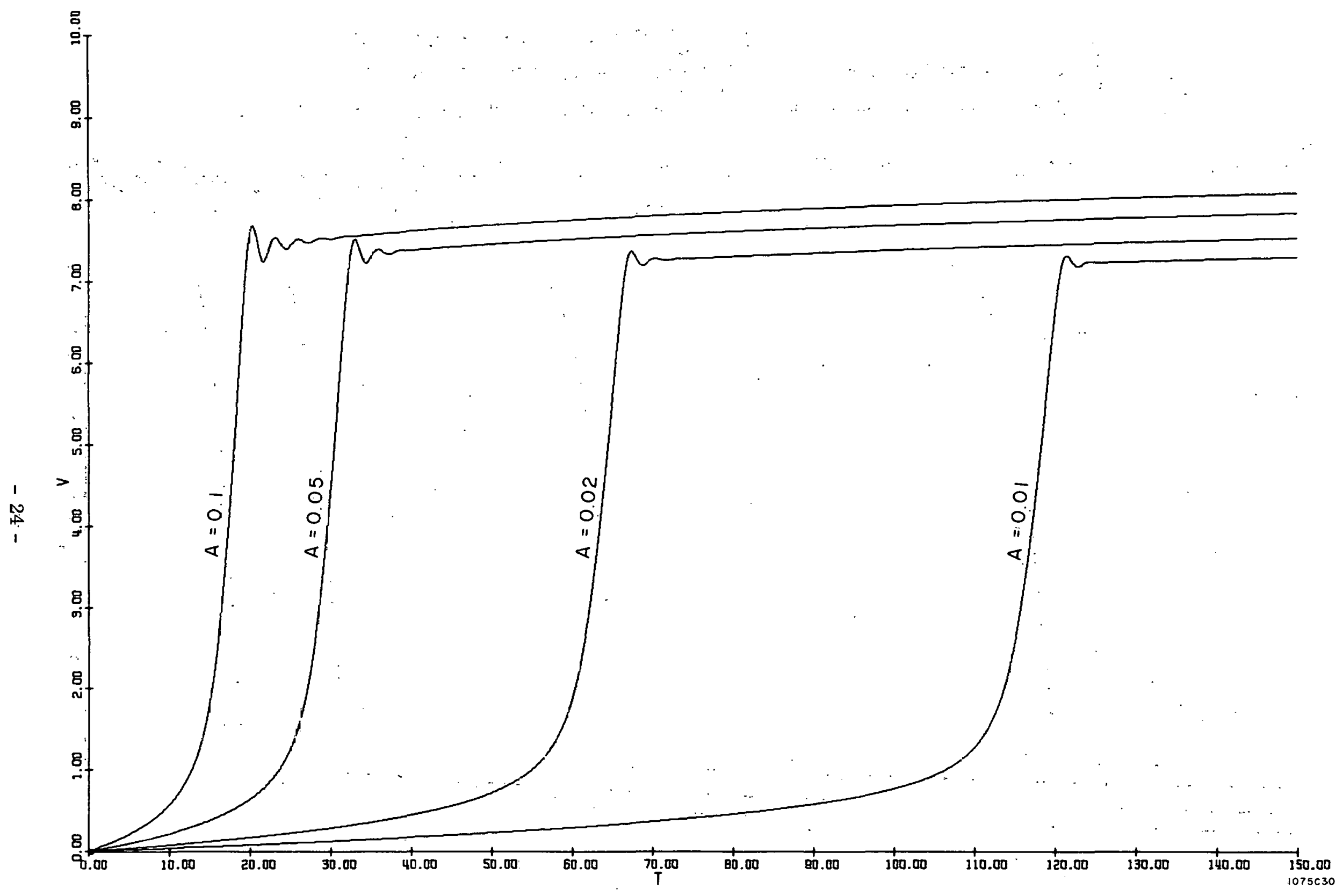

FIG. $7(b)--$ Normalized output voltage $V \equiv v_{\text {out }} / V_{p}$ as function of normalized time $T \equiv I_{p} t /\left(C_{1} V_{p}\right)$ with the normalized drive current slope $A \equiv C_{1} v_{p} k / I_{p}^{2}$ as parameter for $C_{2} / C_{1}=0.2$. Normalized inductance $\mathrm{L} \equiv \mathrm{I}_{\mathrm{p}}^{2} \mathrm{~L}_{1} /\left(\mathrm{v}_{\mathrm{p}}^{2} \mathrm{C}_{1}\right)=0.2$. 


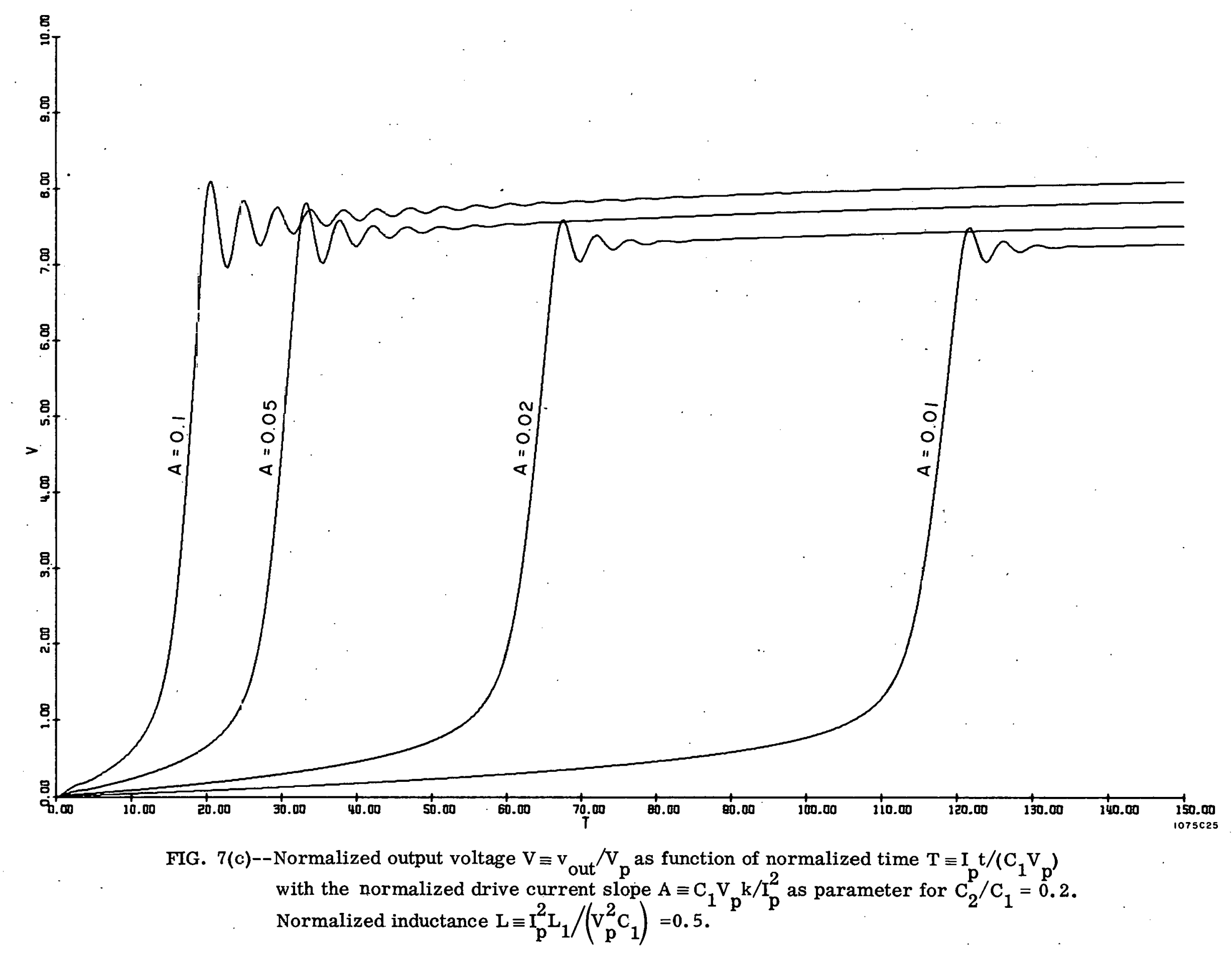




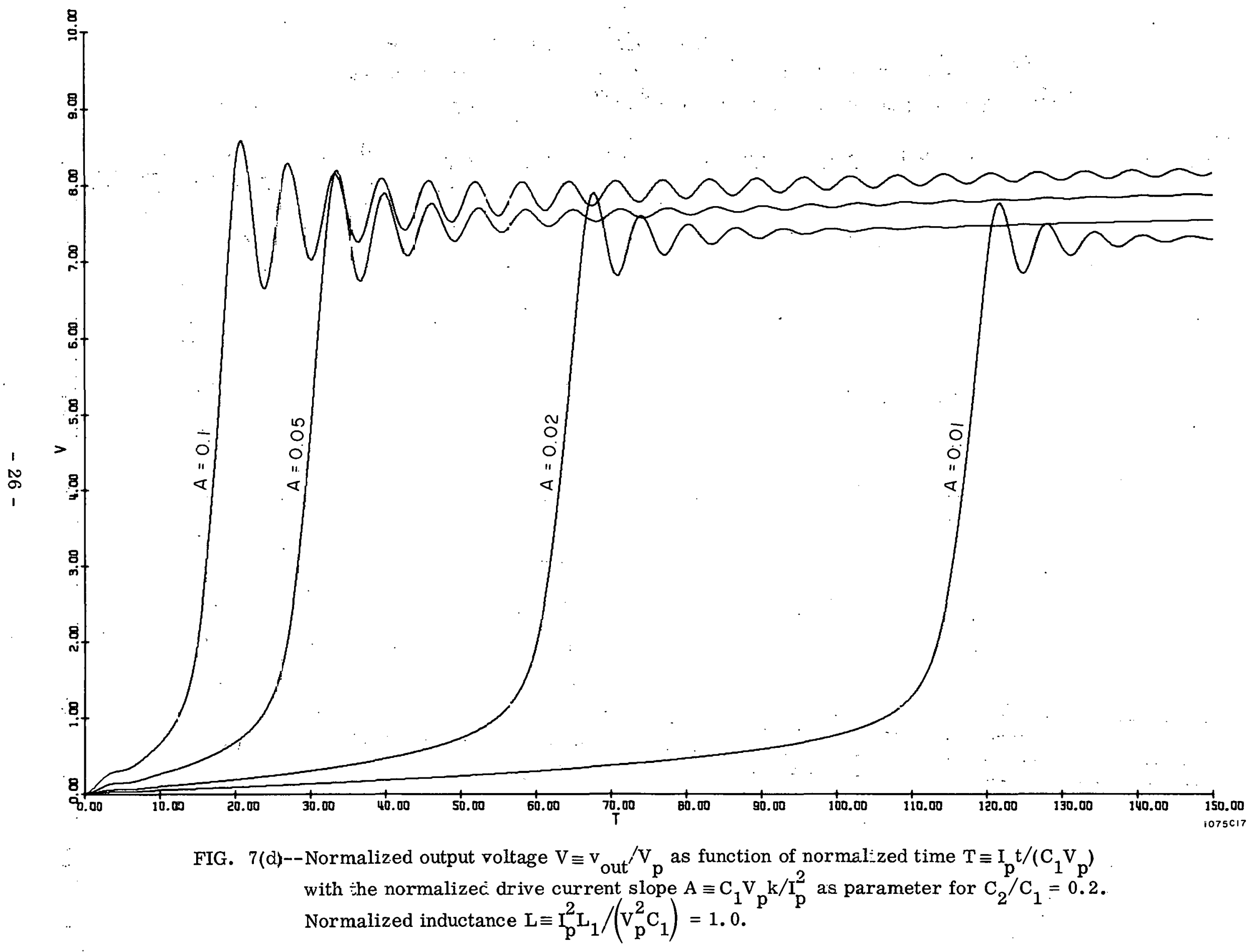




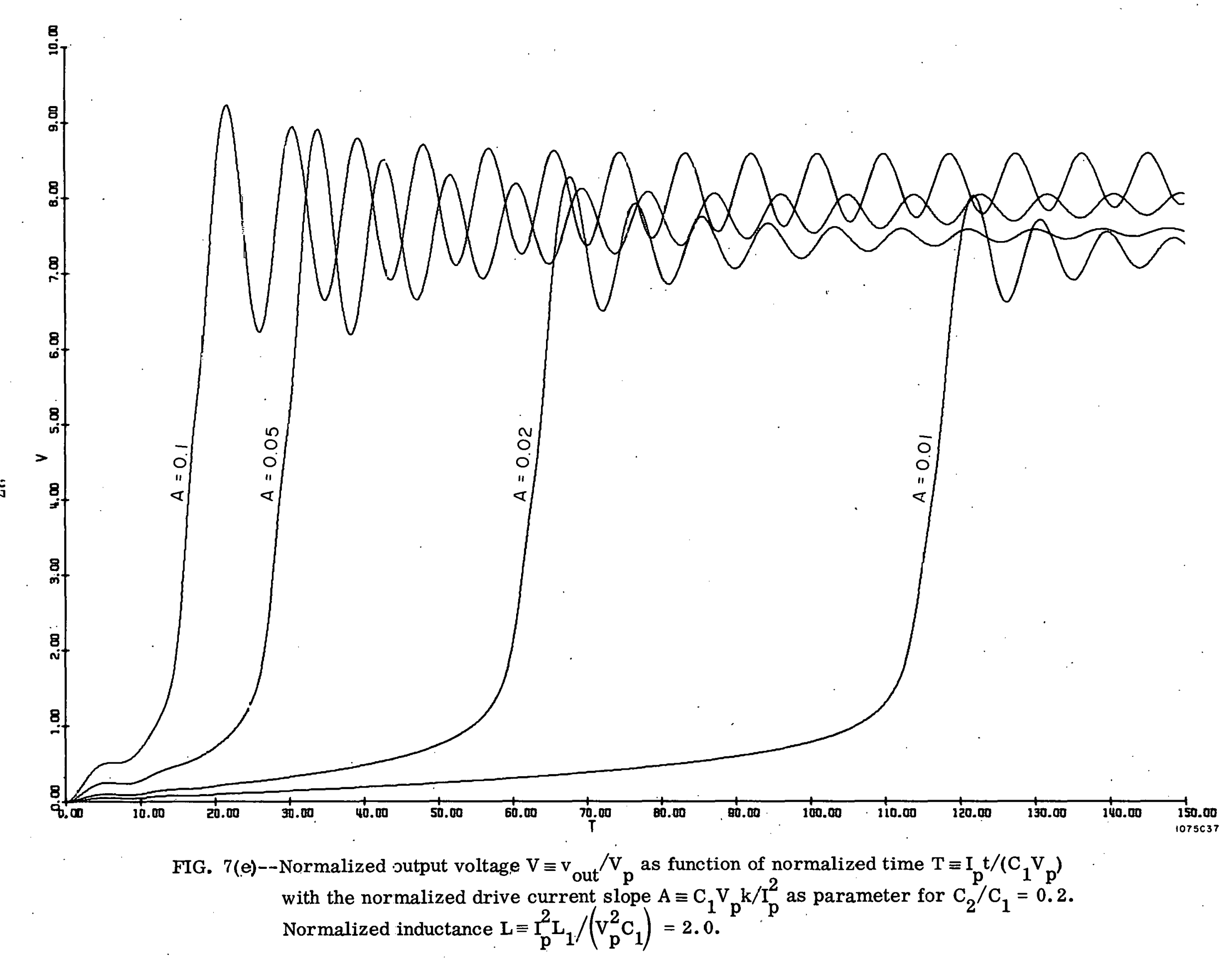




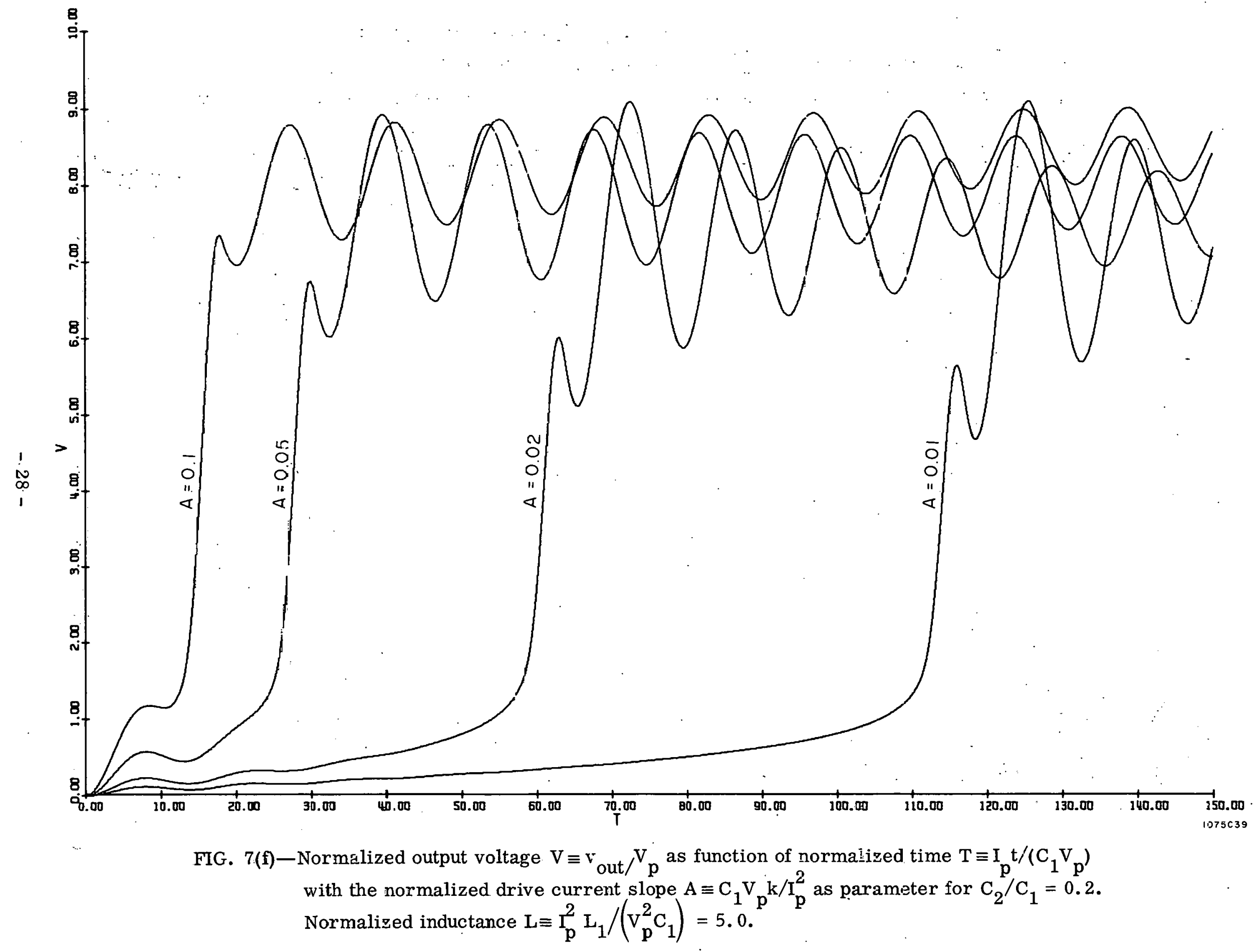




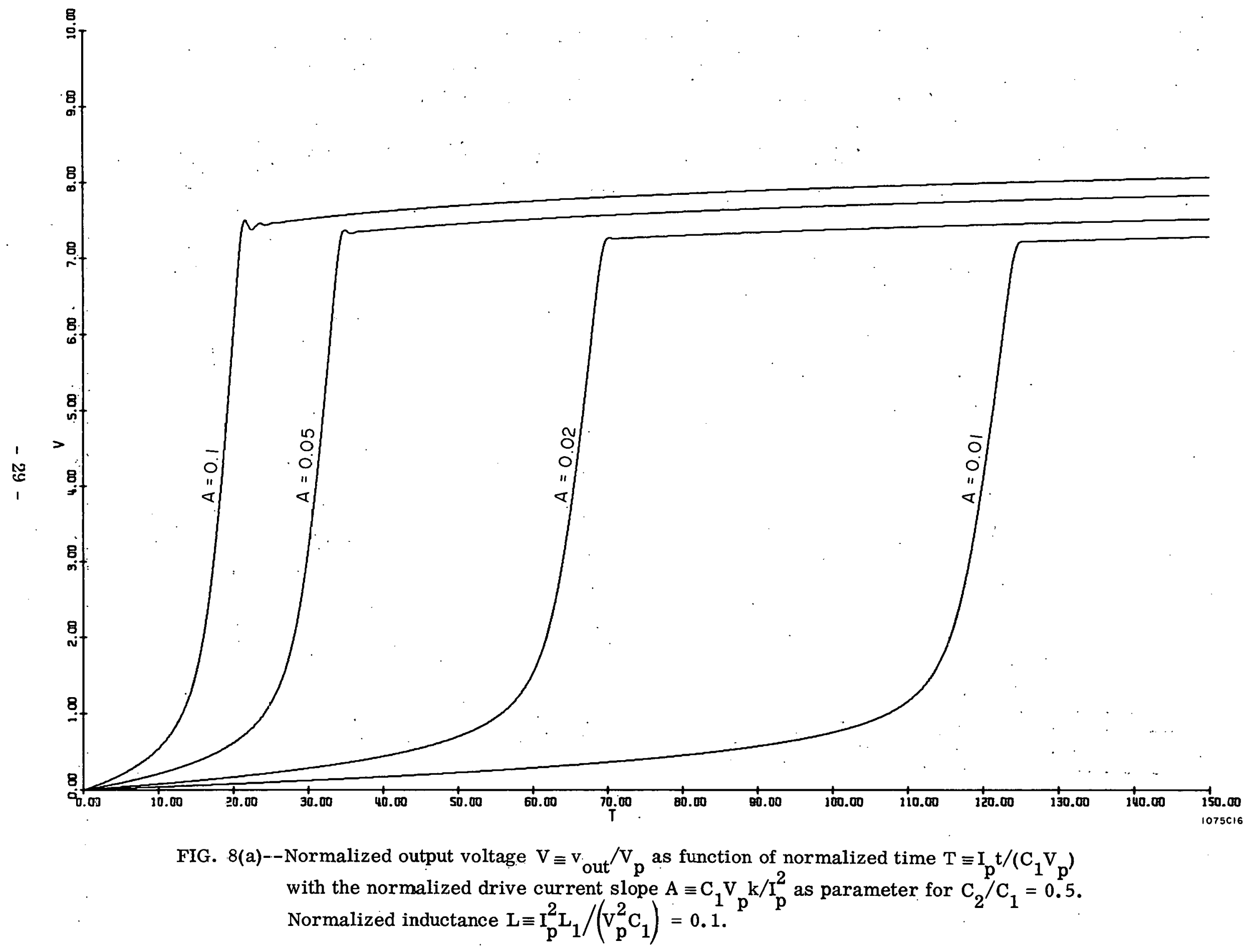




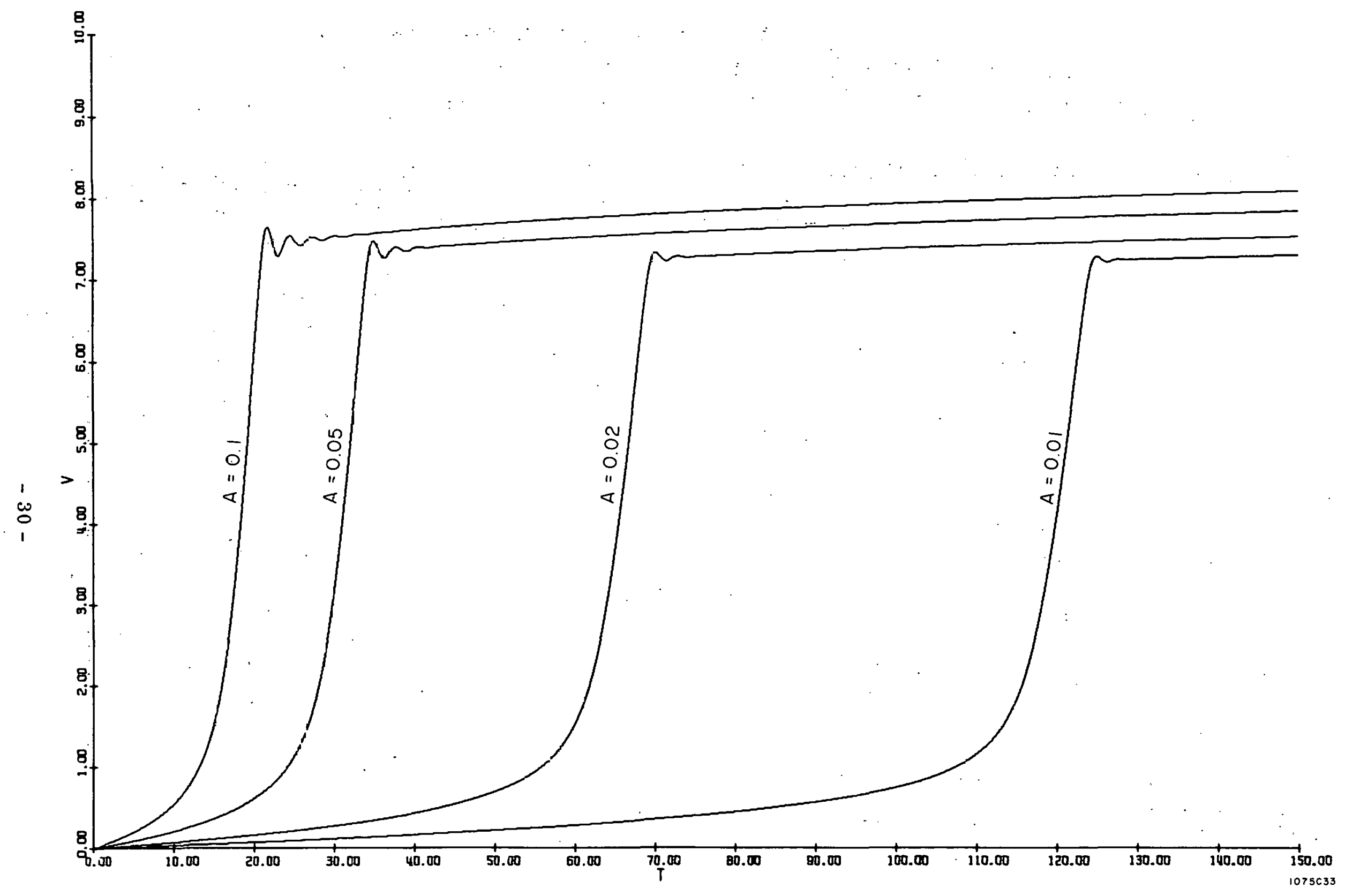

FIG. $8(b)--$ Normalized output voltage $V \equiv v_{\text {out }} / \mathrm{V}_{p}$ as function of normalized time $T \equiv I_{p} t /\left(C_{1} V_{p}\right)$ with' the normalized drive current slope $A \equiv C_{1} V_{p} k / I_{p}^{2}$ as parameter for $C_{2} / C_{1}=0.5$. Normalized inductance $\mathrm{L} \equiv \mathrm{I}_{\mathrm{p}}^{2} \mathrm{~L}_{1} /\left(\mathrm{V}_{\mathrm{p}}^{2} \mathrm{C}_{1}\right)=0.2$. 


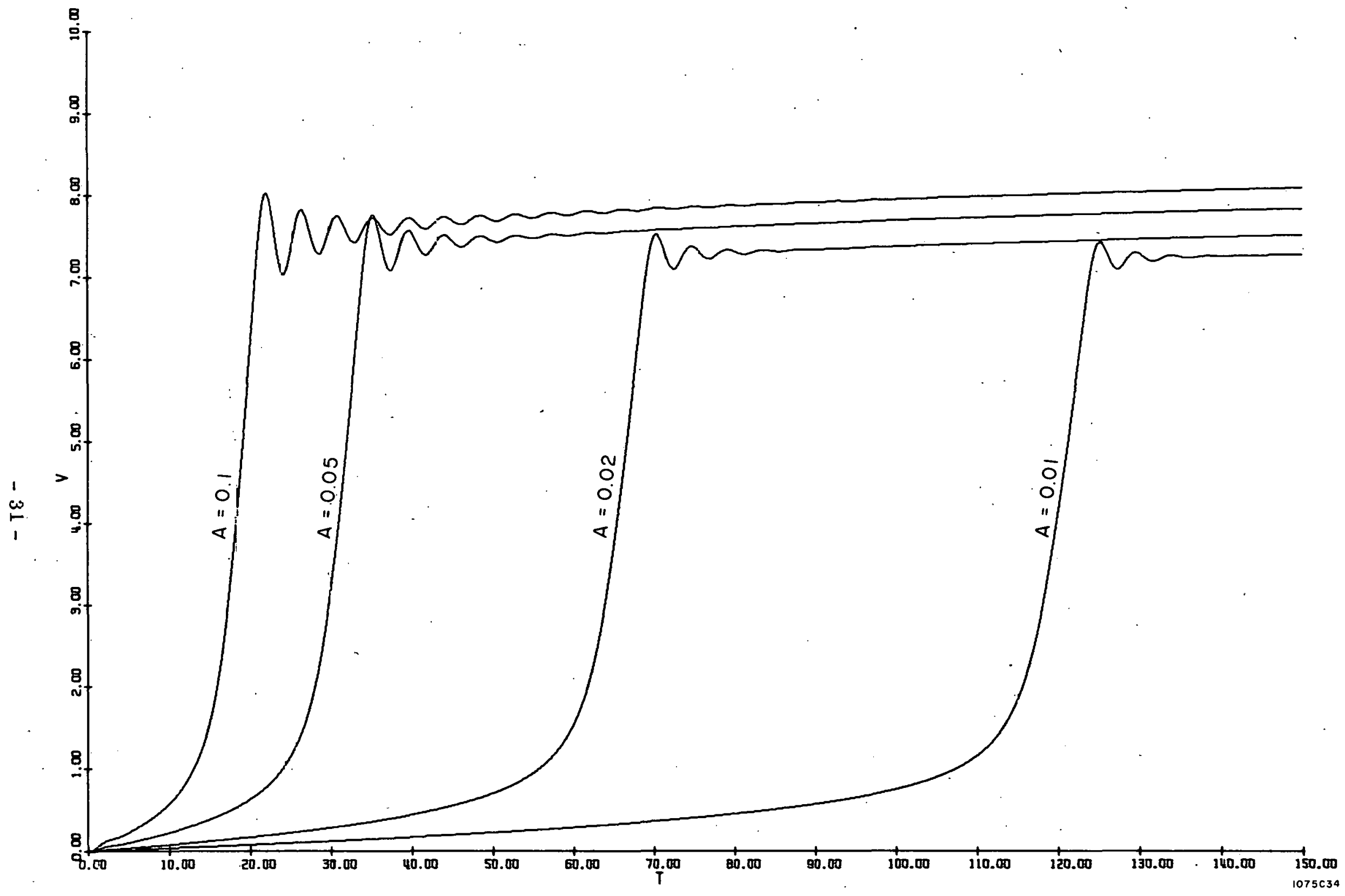

FIG. $8(c)$--Normalized output voltage $V \equiv v_{\text {out }} / \mathrm{V}_{p}$ as function of normalized time $T \equiv I_{p} t /\left(C_{1} v_{p}\right)$ with the normalized drive current slope $A \equiv C_{1} V_{p} k / I_{p}^{2}$ as parameter for $C_{2} / C_{1}=0.5$. Normalized inductance $L \equiv \mathrm{I}_{\mathrm{p}}^{2} \mathrm{~L}_{1} /\left(\mathrm{v}_{\mathrm{p}}^{2} \mathrm{C}_{1}\right)=0.5$. 


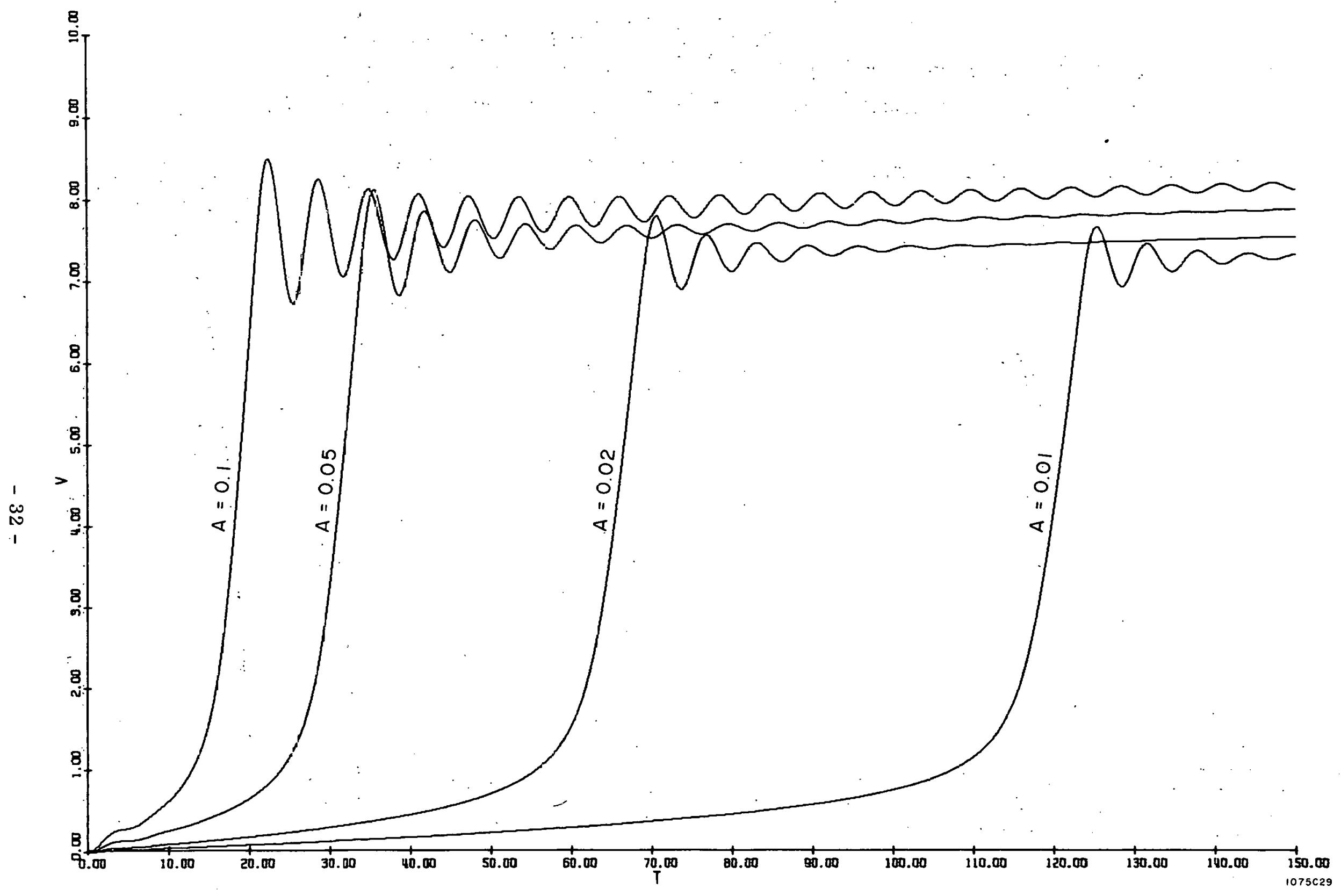

FIG. 8 (d)--Normalized output voltage $V \equiv v_{\text {out }} / \mathrm{v}_{p}$ as function of normalized time $T \equiv I_{p} t /\left(C_{1} V_{p}\right)$ with the normalized drive current slope $A \equiv \mathrm{C}_{1} \mathrm{~V}_{\mathrm{p}} \mathrm{k} / \mathrm{I}_{\mathrm{p}}^{2}$ as parameter for $\mathrm{C}_{2} / \mathrm{C}_{1}=0.5$. Normalized inductance $\mathrm{L} \equiv \mathrm{I}_{\mathrm{p}}^{2} \mathrm{~L}_{1} /\left(\mathrm{v}_{\mathrm{p} .}^{2} \mathrm{C}_{1}\right)=1.0$. 


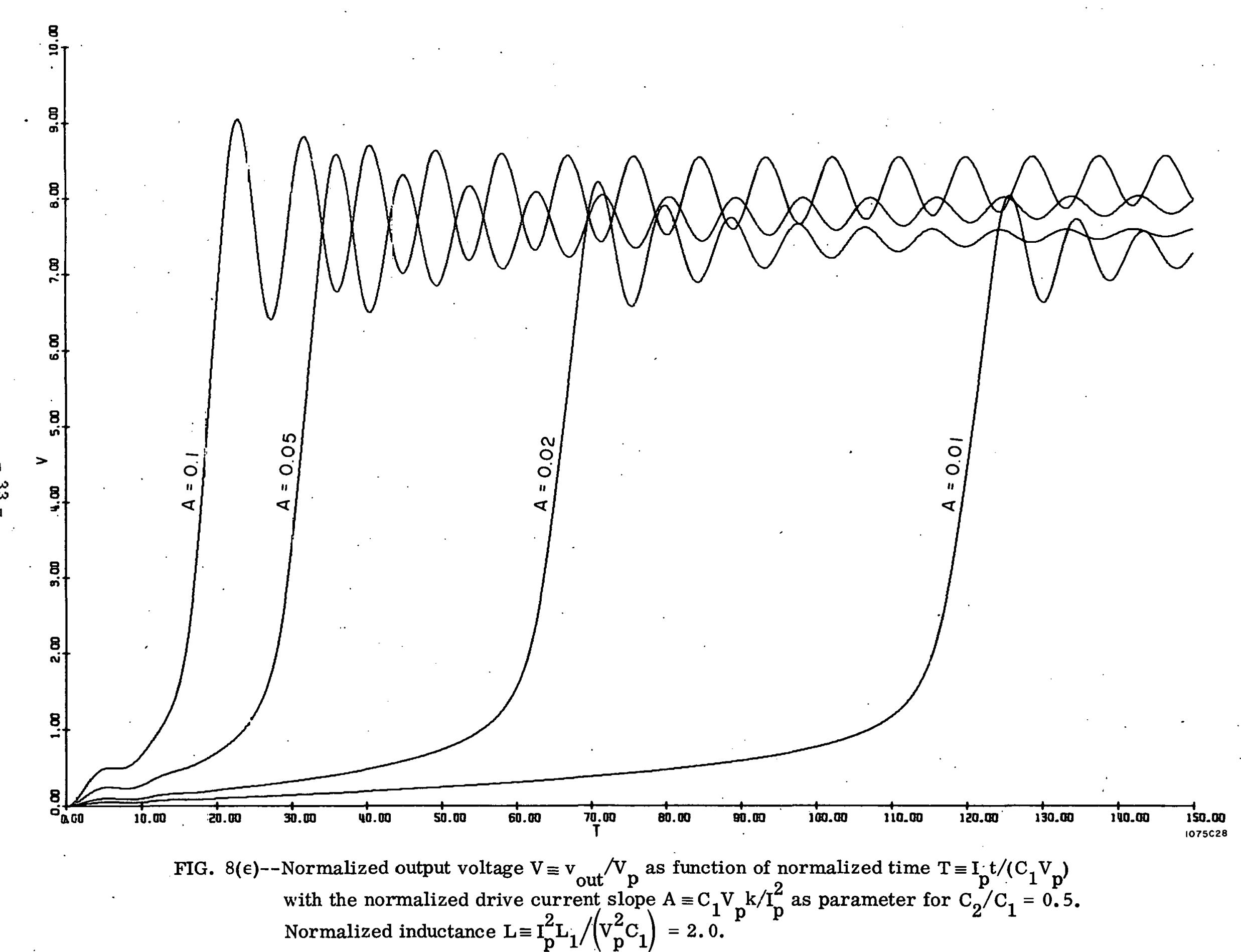




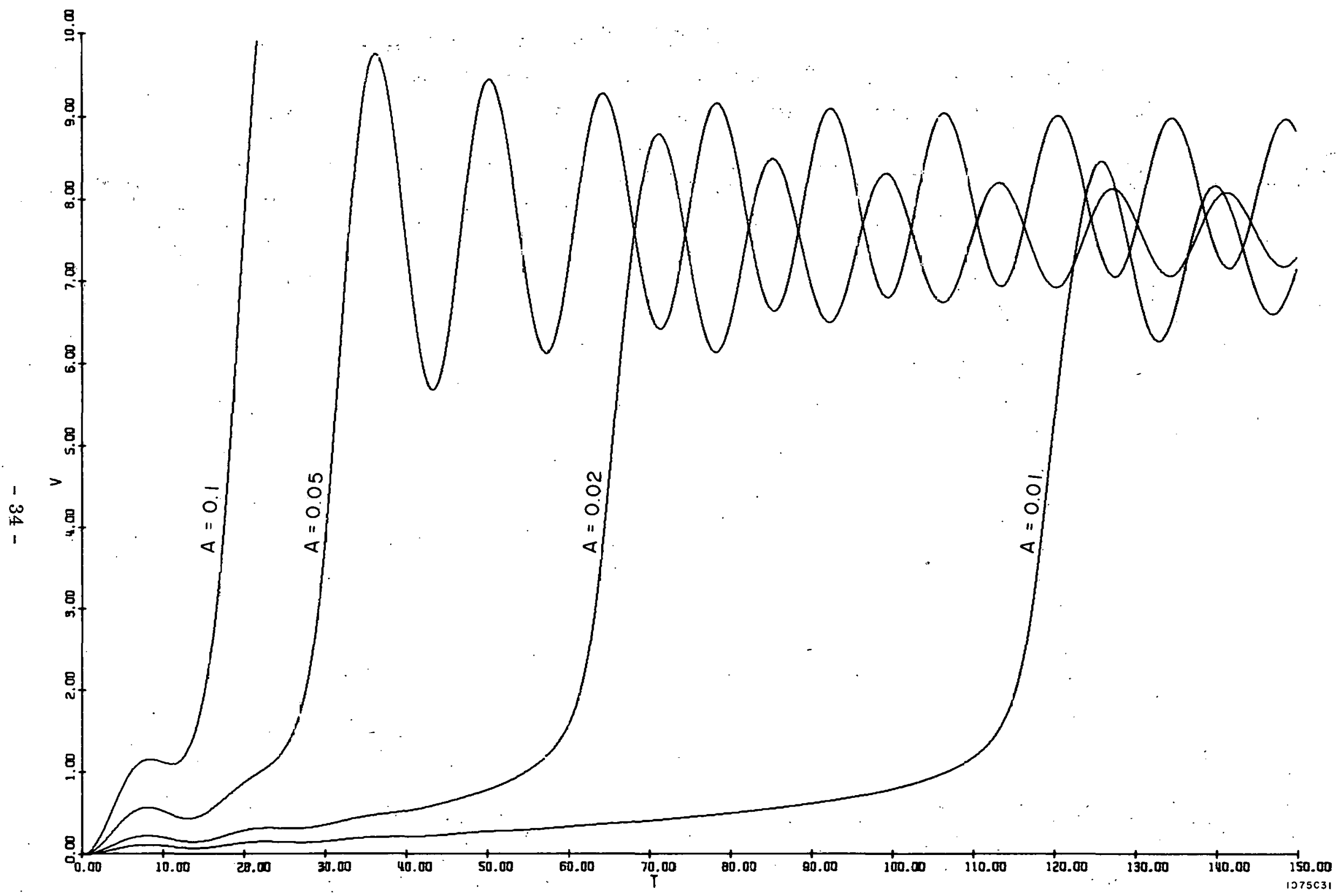

FIG. $8(f)-N o r m a l i z e d$ output voltage $V \equiv v_{\text {out }} / v_{p}$ as function of normalized time $T \equiv I_{p} t /\left(C_{1} V_{p}\right)$ with the normalized drive current slope $A \equiv C_{1} V_{p} k / I_{p}^{2}$ as parameter for $C_{2} / C_{1}=0.5$. Normalized inductance $\mathrm{L} \equiv \mathrm{I}_{\mathrm{p}}^{2} \mathrm{~L}_{1} /\left(\mathrm{V}_{\mathrm{p}}^{2} \mathrm{C}_{1}\right)=5.0$. 


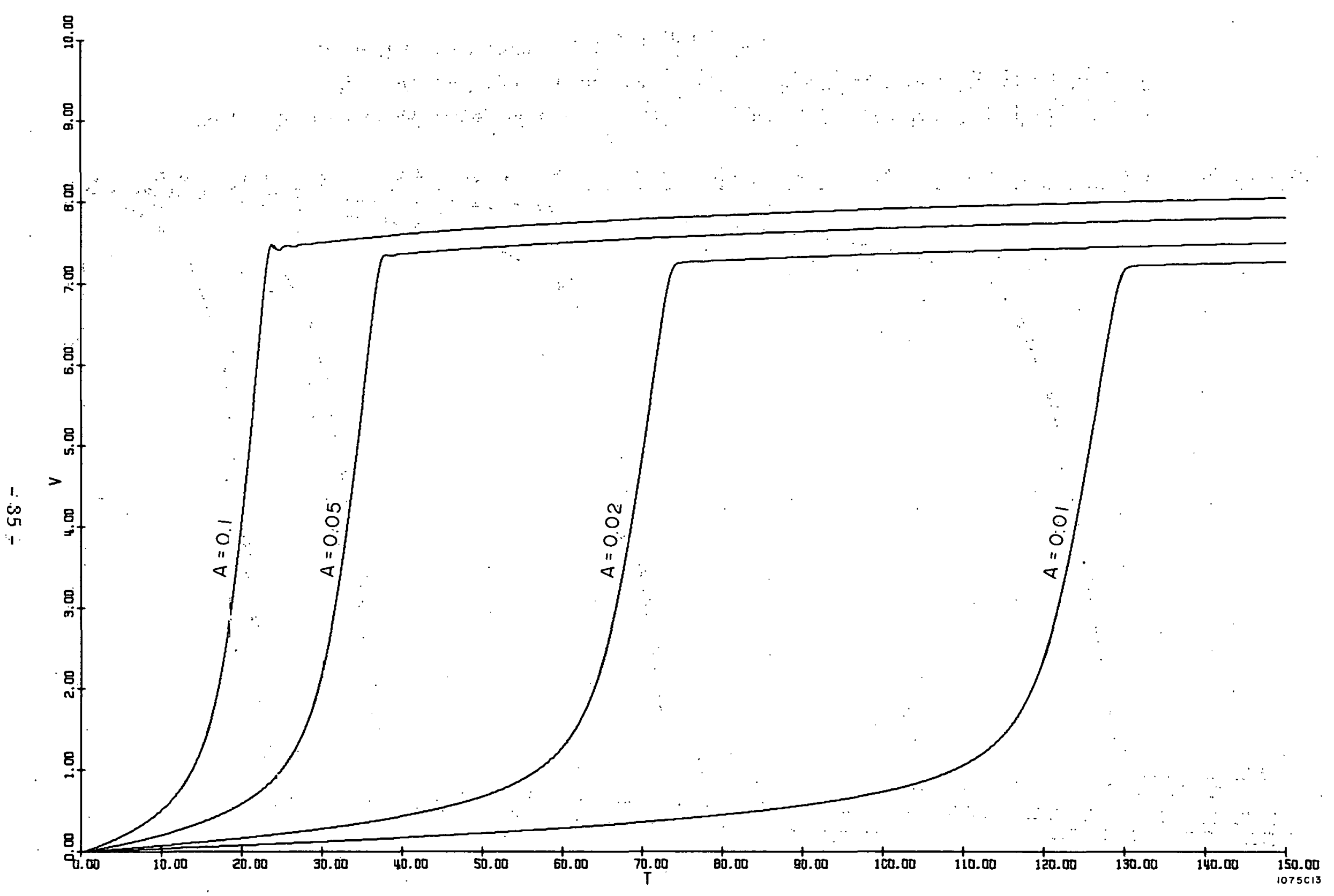

FIG. 9(a)--Normalized output voltage $V \equiv v_{\text {out }} / \mathrm{V}_{\mathrm{p}}$ as function of normalized time $T \equiv \mathrm{I}_{\mathrm{p}} \mathrm{t} /\left(\mathrm{C}_{1} \mathrm{~V}_{\mathrm{p}}\right)$ with the normalized drive current slope $A \equiv C_{1} v_{p} k / I_{p}^{2}$ as parameter for $C_{2} / C_{1}=1.0$. Normalized inductance $\mathrm{L} \equiv \mathrm{I}_{\mathrm{p}}^{2} \mathrm{~L}_{1} /\left(\mathrm{V}_{\mathrm{p}}^{2} \mathrm{C}_{1}\right)=0.1$. 


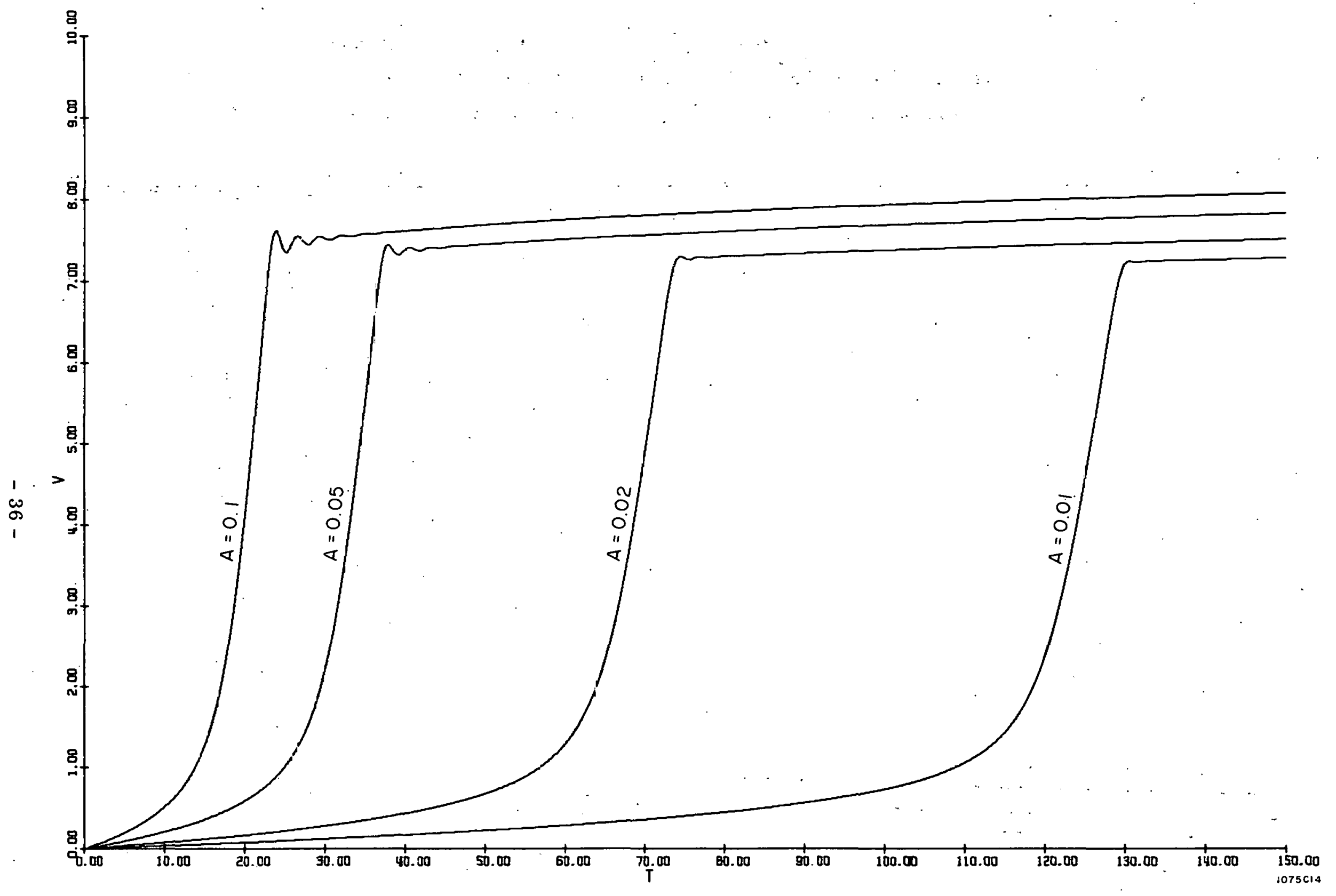

FIG. 9(b)--Normalized output voltage $V_{\equiv} \equiv v_{\text {out }} / V_{p}$ as function of normalized time $T \equiv I_{p} t /\left(C_{1} V_{p}\right)$ with the normalized drive current slope $A \equiv C_{1} V_{p} k / I_{p}^{2}$ as parameter for $C_{2} / C_{1}=1$. 0 . Normalized inductance $\mathrm{L} \equiv \mathrm{I}_{\mathrm{p}}^{2} \mathrm{~L}_{1} /\left(\mathrm{v}_{\mathrm{p}}^{2} \mathrm{C}_{1}\right)=0.2$. 


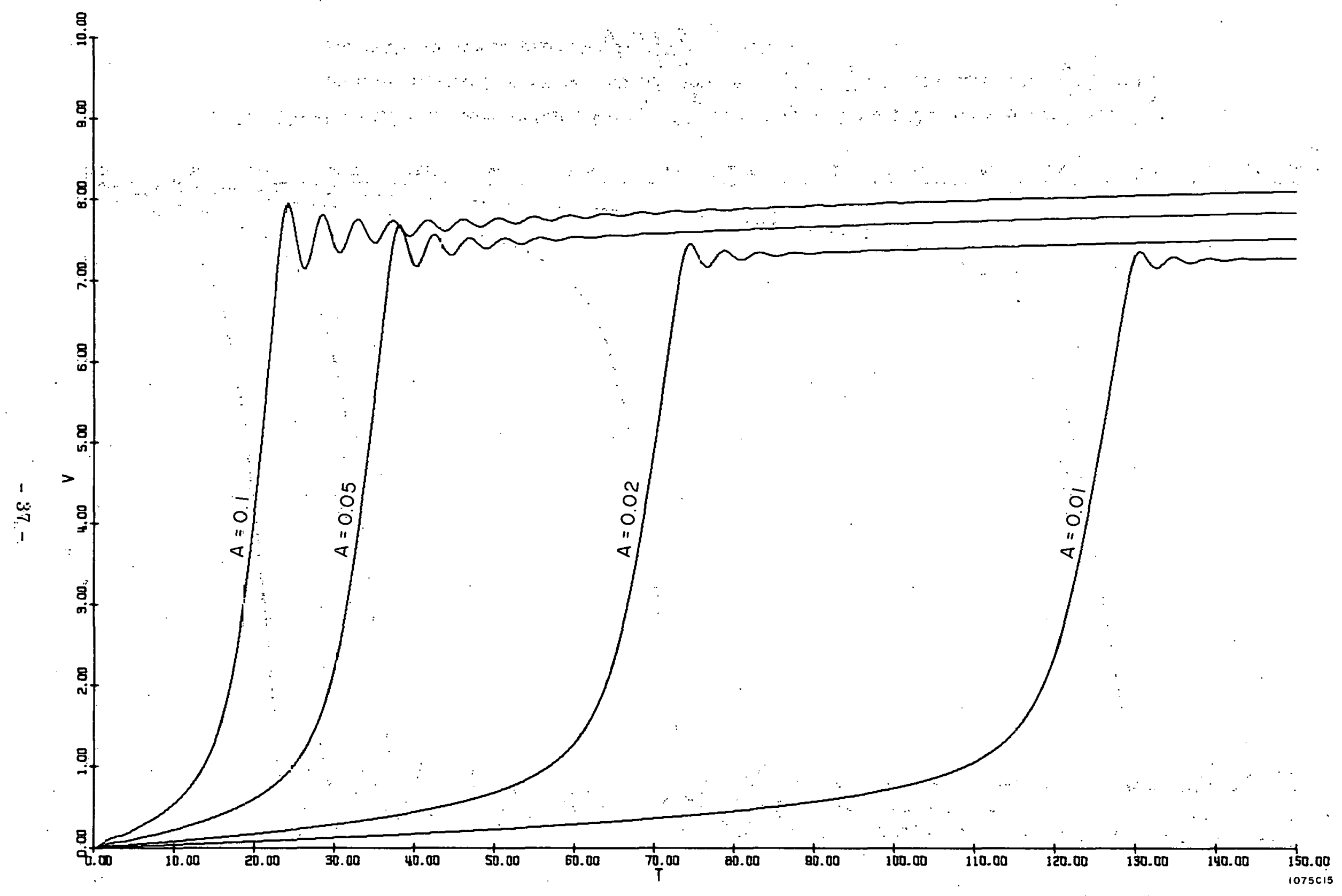

FIG. $9(\mathrm{c})--$ Normalized output voltage $V \equiv v_{\text {out }} / \mathrm{V}_{\mathrm{p}}$ as function of normalized time $T \equiv \mathrm{I}_{\mathrm{p}} t /\left(\mathrm{C}_{1} \mathrm{~V}_{\mathrm{p}}\right)$ with the normalized drive current slope $A \equiv C_{1} V_{p} k / I_{p}^{2}$ as parameter for $C_{2} / C_{1}=1$. 0 . Normalized inductance $\mathrm{L} \equiv \mathrm{I}_{\mathrm{p}}^{2} \mathrm{~L}_{1} /\left(\mathrm{V}_{\mathrm{p}}^{2} \mathrm{C}_{1}\right)=0.5$. 


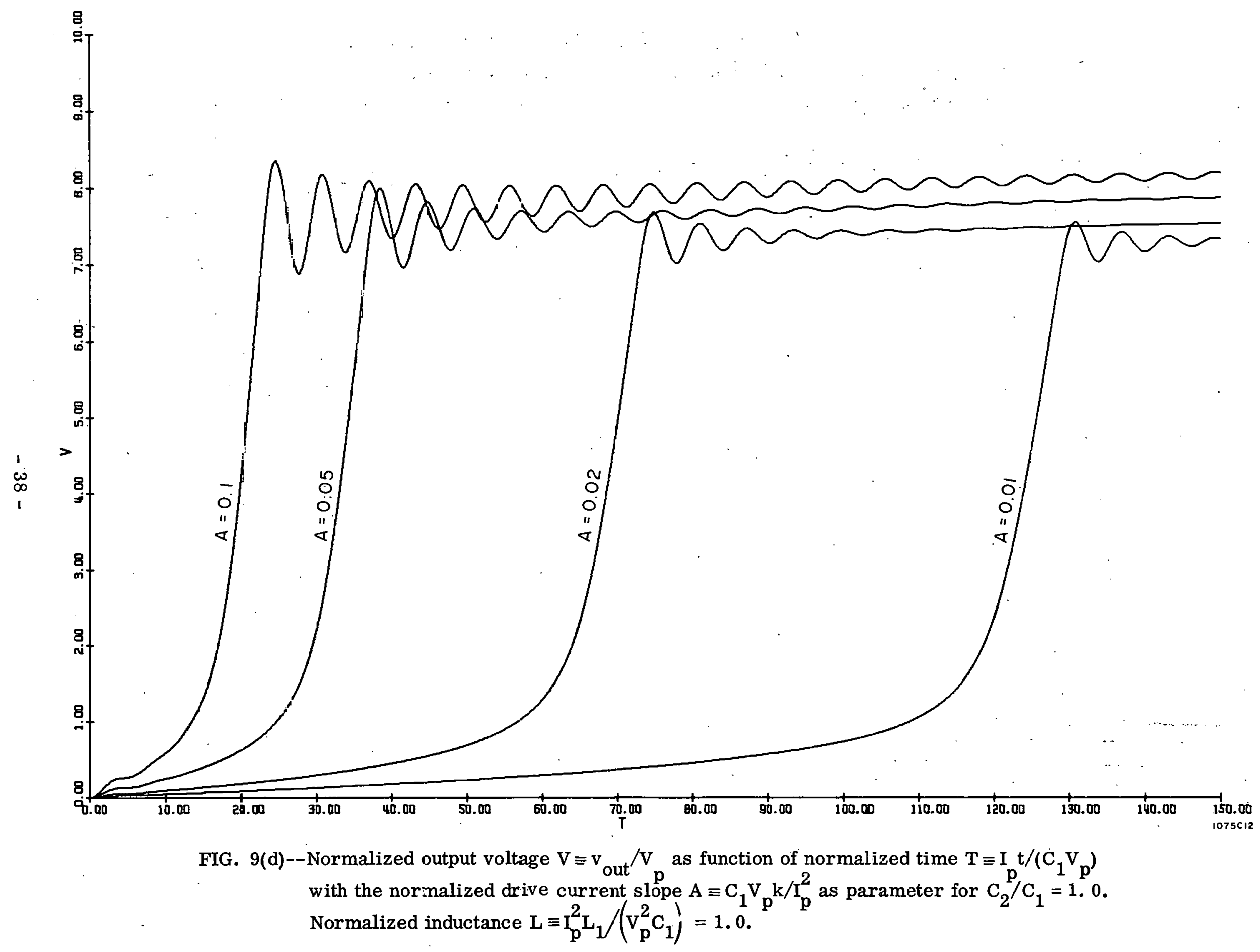




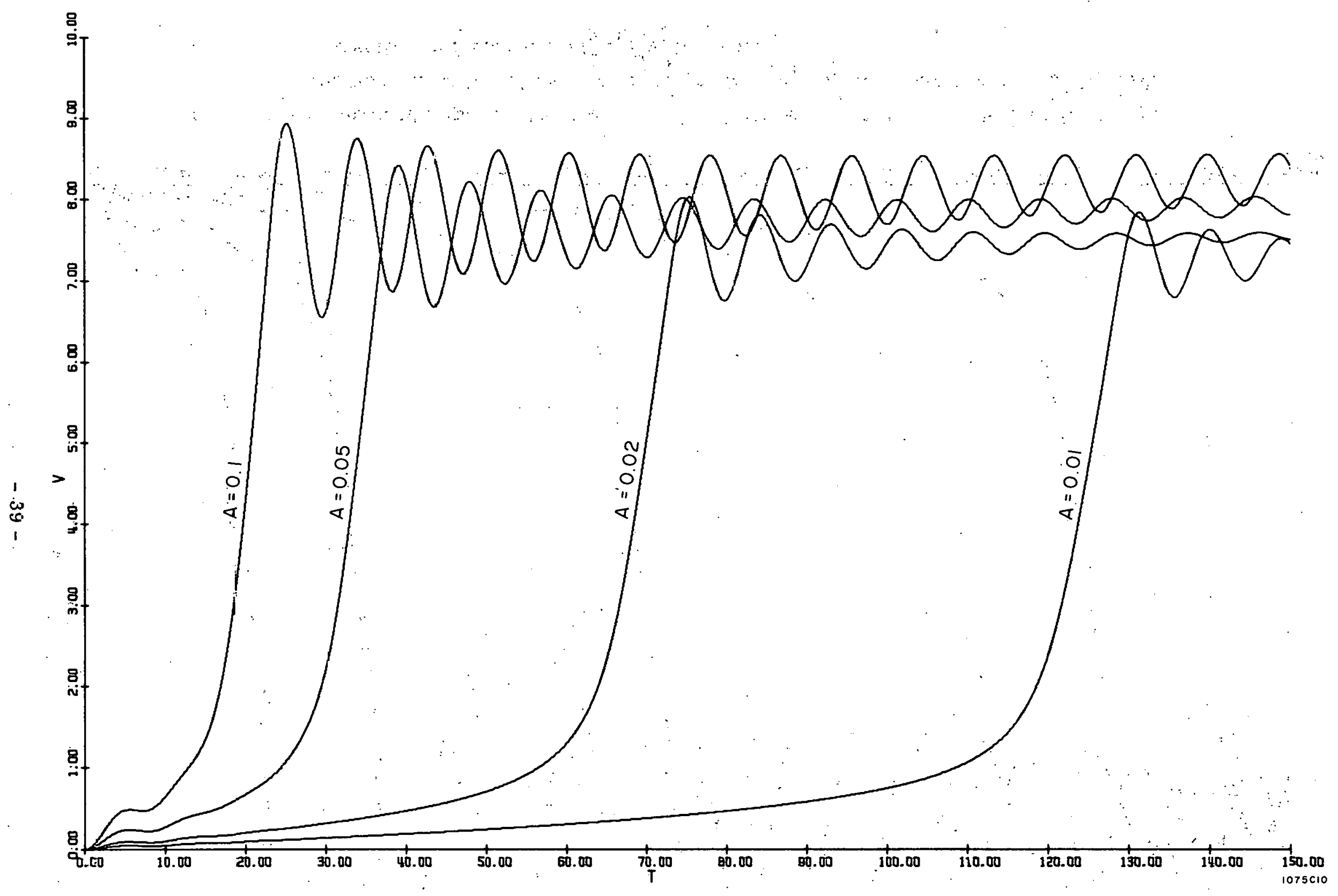

FIG. 9(e)--Normalized output voltage $V \equiv v_{\text {out }} / v_{p}$ as function of normalized time $T \equiv I_{p} t /\left(C_{1} V_{p}\right)$ with the normalized drive current slope $A \equiv C_{1} V_{p} k / I_{p}^{2}$ as parameter for $C_{2} / C_{1}=1$. 0 . Normalized inductance $\mathrm{L} \equiv \mathrm{I}_{\mathrm{p}}^{2} \mathrm{~L}_{1} /\left(\mathrm{v}_{\mathrm{p}}^{2} \mathrm{C}_{1}\right)=2.0$. 


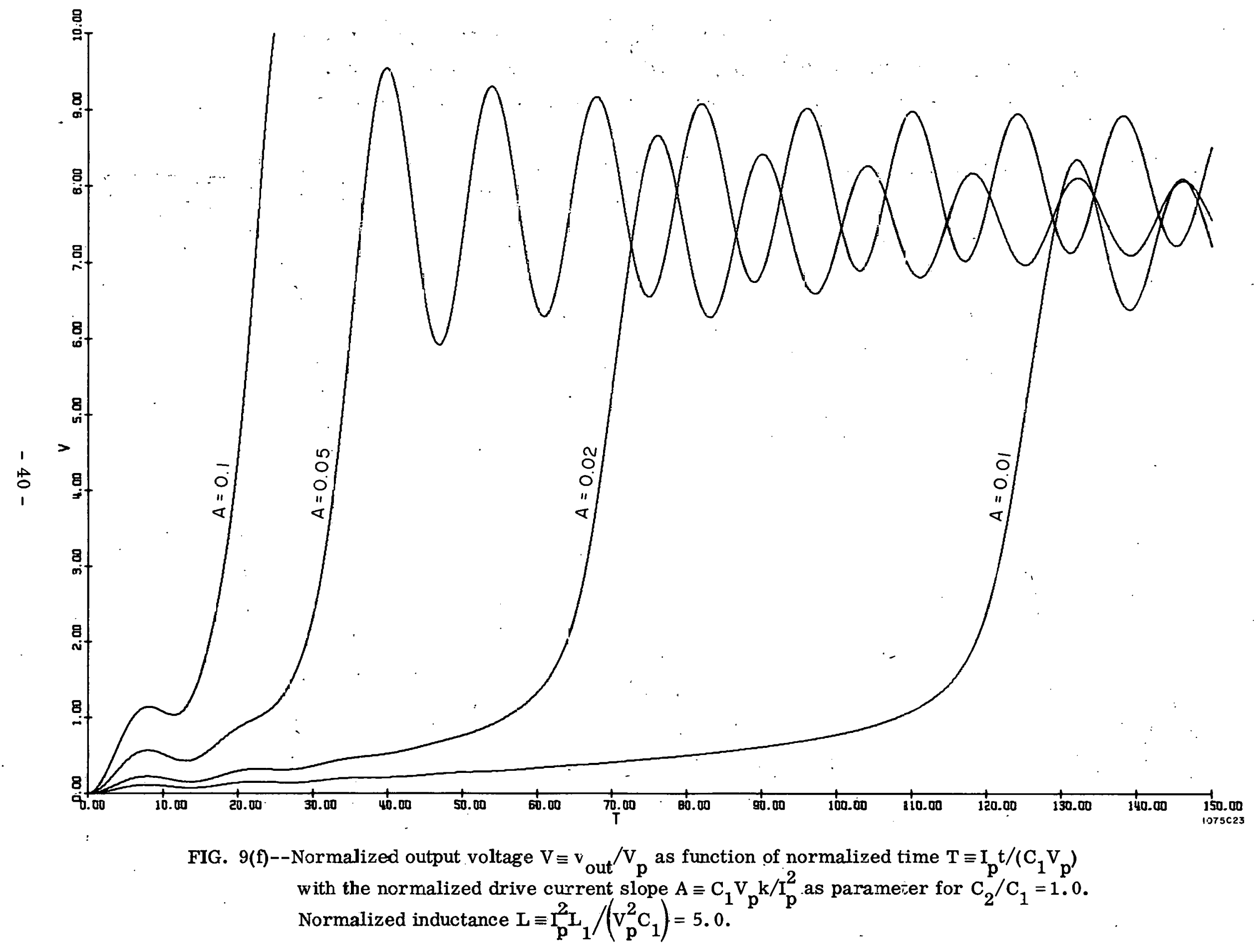


FUNCTION FI(Y,B1,B2)

$B 2 Y=B 2 * Y$

IF $B Z \angle Y . G T .150 .0) B 2 Y=150.0$

IFIY .LT . -100.0$) Y=-100.0$

$F 1=Y * \operatorname{EXP}(1-Y)+1 E-10 * B 1 * E X P(B 2 Y)$

RETURN

END

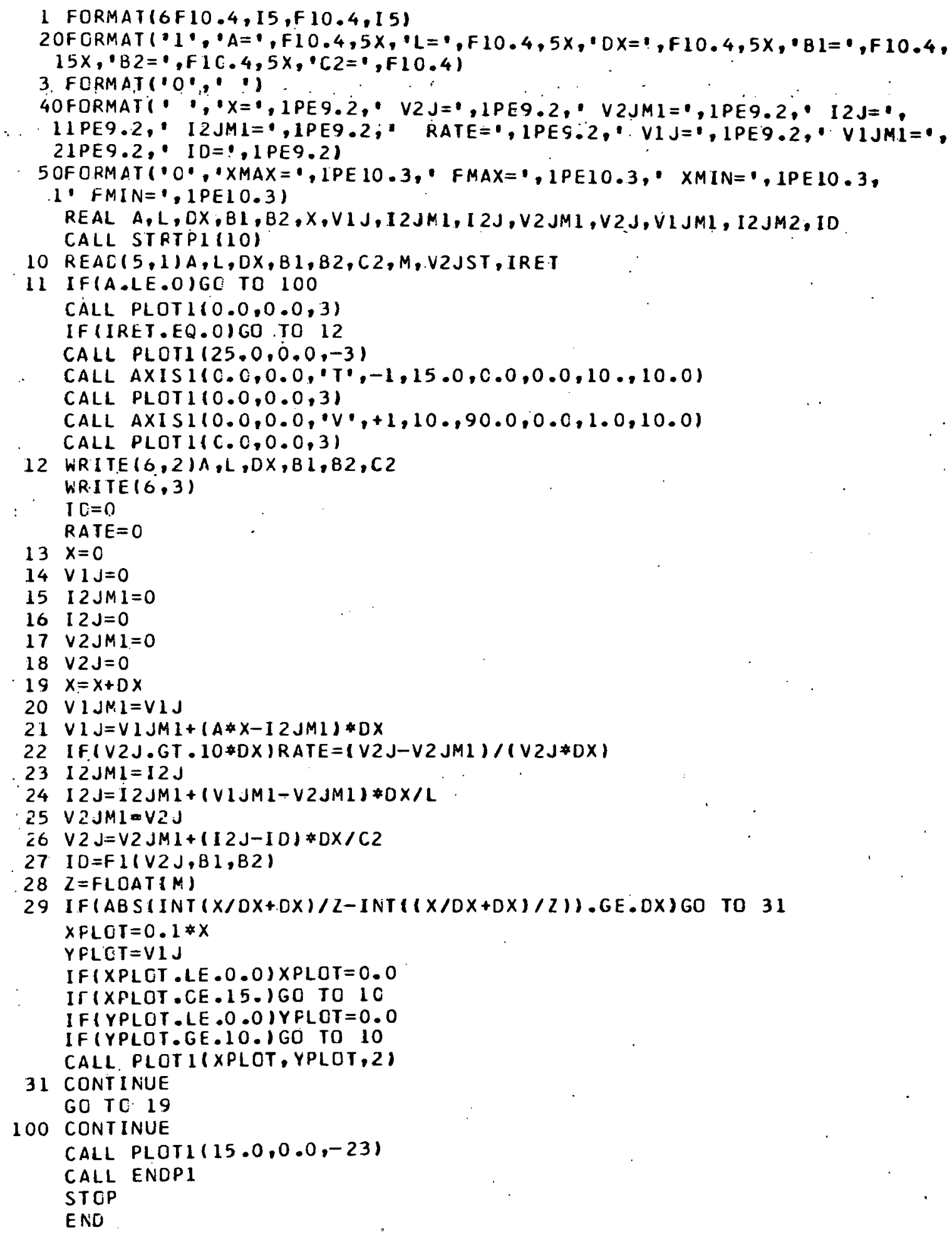

FIG. 10--Fortran-H computer program. 
REFERENCE

1. A. Barna, "On the Intrinsic Time Variance of Fast Timing Circuits Using Tunnel Diodes," Proc. IEEE Letters, (Nov. 1967); pp 2054-2055. 